\title{
Pluripotency-Independent Induction of Human Trophoblast Stem Cells from Fibroblasts
}

Moriyah Naama ${ }^{1}$, Ahmed Radwan ${ }^{1}$, Valery Zayat ${ }^{2}$, Shulamit Sebban ${ }^{1}$, Moran Rahamim ${ }^{1}$, Rachel Lasry ${ }^{1}$,

Mohammad Jaber ${ }^{1}$, Ofra Sabag ${ }^{1}$, Hazar Yassen ${ }^{1}$, Dana Orzech ${ }^{1}$, Areej Khatib ${ }^{1}$, Silvina Epsztejn- 5

Litman $^{3,4}$, Michal Novoselsky-Persky ${ }^{5}$, Kirill Makedonski ${ }^{1}$, Noy Deri ${ }^{1}$, Debra Goldman-Wohl ${ }^{5}$, Howard 6

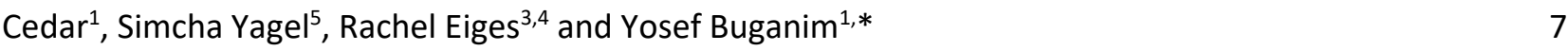

1. Department of Developmental Biology and Cancer Research, The Institute for Medical Research 10 Israel-Canada, The Hebrew University-Hadassah Medical School, Jerusalem 91120, Israel. 11

2. Department of Stem Cell Bioengineering, Mossakowski Medical Research Centre, Polish Academy 12 $\begin{array}{ll}\text { of Sciences, Warsaw, Poland. } & 13\end{array}$

3. Stem Cell Research Laboratory, Medical Genetics Institute, Shaare Zedek Medical Center, 14 $\begin{array}{ll}\text { Jerusalem 91031, Israel. } & 15\end{array}$

4. The Hebrew University School of Medicine, Jerusalem 91120, Israel. 16

5. The Magda and Richard Hoffman Laboratory of Human Placental Research, Department of 17 Obstetrics and Gynecology, Hadassah-Hebrew University Medical Center, Jerusalem, Israel. 18

- Correspondence should be addressed to Y.B. (yossibug@ekmd.huji.ac.il) 19 


\section{SUMMARY}

Recent studies demonstrated that human trophoblast stem-like cells (hTS-like cells) can be derived

from naïve embryonic stem cells or be induced from somatic cells by the pluripotency factors, OSKM

This raises two main questions; (i) whether human induced TSCs (hiTSCs) can be generated

both male and female fibroblasts. By using single and double knockout (KO) fibroblasts for major 35

pluripotency genes (i.e. SOX2 or NANOG/PRDM14) we show that GOKM not only is capable of 36 generating hiTSCs from the KO cells, but rather that the efficiency of the process is increased. Through 37 H3K4me2 and chromatin accessibility profiling we demonstrate that GOKM target different loci and 38 genes than OSKM, and that a significant fraction of them is related to placenta and trophoblast 39 function. Moreover, we show that GOKM exert a greater pioneer activity compared to OSKM. While 40 GOKM target many specific hTSC loci, OSKM mainly target hTSC loci that are shared with hESCs. Finally, we reveal a gene signature of trophoblast-related genes, consisting of 172 genes which are highly 42 expressed in blastocyst-derived TSCS and GOKM-hiTSCs but absent or mildly expressed in OSKMhiTSCs.

Taken together, these results imply that not only is the pluripotent state, and SOX2 specifically, not 45 required to produce functional hiTSCs, but that pluripotency-specific factors actually interfere with 46 the acquisition of the hTSC state during reprogramming. 


\section{INTRODUCTION}

For an extensive period of time, all attempts to isolate and propagate human TSCs (hTSCs) in vitro had

failed due to lack of knowledge of the culture conditions required for the maintenance of these cells.

Recently, such culture conditions were identified and for the first time hTSCs were successfully derived

and propagated from blastocysts and first trimester trophoblasts ${ }^{1}$. Following differentiation, these

hTSCs gave rise to all major trophoblast cell types, exhibited transcriptional and epigenetic signatures risk factors at early stages of implantation, as it is currently impossible to derive hTSCs from disease-

Alternatively, the ability to convert fibroblasts into other cell types ${ }^{2}$ by a defined number of transcription factors opens an attractive avenue which resolves this limitation, as mesenchymal cells can be isolated relatively easily from post-gestational tissue, such as term placenta or cord blood following diseaseaffected pregnancies.

Recent studies demonstrated that human induced trophoblast stem cells (hiTSCs) can be generated 64 either by transdifferentiating human naïve pluripotent cells ${ }^{3-8}$ or by forced expression of OCT4, SOX2, 65 KLF4 and MYC (OSKM) in fibroblasts ${ }^{3,9}$. In these approaches the efficiency and quality of the cells was dependent on the initial acquisition of pluripotency and the use of naïve human embryonic stem cell (hESC) culture conditions or on the pluripotency OSKM factors. Thus, it is still unclear whether human resemble human blastocyst-derived TSCs (hbdTSCs).

Moreover, by profiling the transcriptome and chromatin (i.e. ATAC-seq and ChIP-seq for H3K4me2) at 
more efficient in producing hiTSCs than OSKM and that the TSC state achieved by GOKM bypasses

pluripotency. These data suggest that fully functional hiTSCs can be directly generated from human

Ectopic expression of GATA3, OCT4, KLF4 and MYC in fibroblasts generates stable colonies that are 87 similar in their morphology and marker expression to human trophoblast stem cells

Previously, we and others have shown that transient ectopic expression of four mouse key 89 trophectoderm (TE) genes, Gata3, Eomes, Tfap2c and Myc/Ets2 can force fibroblasts to become stable 90 and fully functional mouse induced trophoblast stem cells (miTSCs, ${ }^{10,13}$ ). However, current knowledge 91 suggests that key TE genes vary significantly between human and mouse. Single-cell RNA-seq studies 92 of the human pre-implantation blastocyst revealed that key mouse TE genes such as Eomes and Elf5 93 are absent or expressed at very low levels in the human $T E{ }^{14,15}$. Esrrb, which is expressed in the mouse 94 epiblast ${ }^{16}$ and which plays an important role in the maintenance and induction of pluripotency ${ }^{11,17,18}$ 95 and $\mathrm{mTSCs}^{19}$, is not expressed in the human epiblast, but rather in the TE and primitive endoderm 96 (PE) ${ }^{14,15}$. Another crucial difference between mouse and human blastocysts is the involvement of pluripotency genes such as the key master regulator OCT4 in the establishment of the human TE 98 compartment ${ }^{20}$.

Thus, in order to reprogram fibroblasts into human induced trophoblast stem cells (hiTSCs), we 100 selected transcription factors with a known role in the development of the human trophoblast lineage but also included pluripotent genes based on their suspected necessity for the induction of the hTSC state ${ }^{20-22}$. In total, we cloned seven genes, GATA3, TFAP2C, ESRRB, OCT4, KLF4, SOX2 and MYC, into doxycycline (dox)-inducible lentiviral vectors and used them to infect human foreskin fibroblasts (HFFs). Cells were kept in low (5\%) oxygen conditions and treated with dox for two weeks in basic reprogramming medium (DMEM $+10 \% \mathrm{FBS}$ ) which was gradually switched to $\mathrm{hTSC}$ medium ( ${ }^{1}$, Figure 1A). Following 4 weeks of reprogramming, the induced cells were weaned off dox and allowed to stabilize for 7-10 days, after which individual epithelial-like colonies were manually transferred into 108 separate plates for propagation and analysis. Transgene integration analysis revealed that GATA3, 109 OCT4, KLF4 and MYC (GOKM) were the only transgenes which had been integrated in all examined colonies (Figure S1A), suggesting that the pluripotent gene SOX2 is not required for the induction of the TSC state.

Indeed, transduction of GOKM into two primary HFF lines, namely KEN and PCS201, and one primary 113 adult female patient-derived fibroblast line (GM2), produced stable and dox-independent (Figure S1B) 
blastocyst-derived TSCs (hbdTSCs) following passaging on mouse feeder cells (Figure 1B). The

In order to evaluate the identity of the resultant colonies, expression of hTSC markers was assessed. similar to mouse cells ${ }^{10}$.

Human trophoblast is known to have a unique expression pattern of HLA proteins, including a lack of hiTSC and hbdTSC lines (Figure S1F, ${ }^{24}$ ).

Expression of hTSC markers GATA3, GATA2, TFAP2C and KRT7, epithelial markers CDH1 and KRT18, as

\section{The transcriptome of hiTSCs is highly similar to hbdTSCs}

Extensive nuclear reprogramming during somatic cell conversion should ideally result in the activation 
and hbdTSC\#9), two parental primary fibroblast lines (KEN and GM2) and two pluripotent stem cell

(PSC) clones (hESCs and hiPSC\#1) were used as positive and negative controls, respectively. As OSKM

factors were recently shown to be capable of producing hiTSCs as well ${ }^{3,9}$, we sought to understand

whether the selection of factor combination has any effect on gene expression in the resulting hiTSCs.

To that end, we reprogrammed fibroblasts into hiTSCs using the OSKM factors and profiled the

Scatter plot analysis indicated a highly similar transcriptome between hbdTSCs and hiTSCs with $\mathrm{R}^{2}$ scores ranging between 0.78-0.84, and key hTSC genes such as TP63 and GATA3 showing high levels list according to EnrichR database. NANOG is also featured as a key regulator, likely as a repressor. genes between hiTSC and fibroblasts we identified gene regulatory networks (GRNs) and proteinprotein interactions that are highly associated with the hTSC state ${ }^{22,23,27}$. Among the key regulators of these GRNs are TP63, GATA2, GRHL3, TFAP2A, TFAP2C, ARIDA3, ELF5, TEAD4, KLF5, ETV4, ASCL2, HAND1 and many others (Figure 2E, marked by green octagons).

To test whether small differences in gene expression exist between hiTSC clones and hbdTSCs, we 
OSKM remodel the somatic chromatin in a similar manner during reprogramming. To that end, we profiled the transcriptome and chromatin of cells transduced with GOKM or OSKM using RNA-seq,

Assay for Transposase-Accessible Chromatin using sequencing (ATAC-seq) and chromatin specific to fibroblasts (75,225 peaks), hbdTSCs (49,101 peaks) and hESCs (70,086 peaks, Figure S3A). genes that define each cell type with scatterplots (Figure S3B-D, orange and light blue dots mark peaks that are associated with genes that are expressed in the corresponding cell type (i.e. hbdTSCs or in hESCs) according to RNA-seq data, while red and dark blue dots represent peaks in which no 202 association with gene expression was identified). Low correlation coefficient $\left(R^{2}, 0.065-0.26\right)$ between 203 the three samples, as well as peaks that associated with known cell type-specific genes (e.g. GATA3, TP63 and ELF5 in hbdTSCs, SOX2, SALL4 and NANOG in hESCs, POSTN and THY1 in fibroblasts) validated 
peaks for 'OSKM D3', Figure S3E). These data suggest that already at day 3 of reprogramming, GOKMinduced cells show a bias toward remodeling of chromatin that is associated with hTSC state.

We then focused on the relation between the hbdTSC-specific ATAC-seq peak set and the newly remodeled peaks in 'GOKM D3' and 'OSKM D3'. First, we associated GOKM D3 and OSKM D3 peaks to their neighboring genes and created scatterplots of the peaks which are unique to either GOKM D3 or 3G). For the first group, transcription factor binding site analysis revealed that GOKM remodel the chromatin of genes that are mainly regulated by GATA2 and TP63, transcription factors implicated in the TSC state ${ }^{1}$, while OSKM remodel the chromatin of genes that are predominately regulated by the trophoblast differentiation factor RUNX1 ( ${ }^{31}$, Figure 3C). GO term enrichment analysis identified WNT and DNA damage response as the major pathways for GOKM-regulated genes, while mitochondrial long-chain fatty acid $\beta$ oxidation, G13 and NOTCH signaling were identified as the major pathways for OSKM-regulated genes (Figure 3D).

STRING and iRegulon analysis of the 333 GOKM-regulated genes (Figure 3E) and the 66 OSKMregulated genes (Figure 3F) identified two distinct GRNs with 13 key hTSC transcription factors being expressed already at day 3 of GOKM transduction (blue framed octagons), and $7 \mathrm{hTSC}$ transcription factors, along with OCT4 and SOX2 transgenes, in OSKM-transduced cells (Figure 3E-F). 'GOKM D3'

For the second group, transcription factor binding site and gene perturbation analyses revealed that 
S3G). Transcription factor binding site analysis revealed that GOKM remodel the chromatin of genes

that are mainly regulated by the transcription repressor REST while OSKM remodel the chromatin of genes that are mainly regulated by SUZ12 and KLF4 (Figure S3H). GO term enrichment analysis identified DNA replication and WNT signaling as the major pathways for GOKM-regulated genes, while focal adhesion-PI3K-Akt-mTOR signaling as the major pathway for OSKM-regulated genes (Figure S3I). $\mathrm{S} 3 \mathrm{~L}$ ), but not in remodeling the chromatin of the pluripotent state (Figure S3K).

Given that many pivotal stemness genes are shared between hESCs and hbdTSCs (e.g. LIN28A, FGF4, peaks overlapped solely with hbdTSC peaks but not with OSKM D3, parental fibroblasts or hESCs. In contrast, the 1,739 OSKM-specific peaks overlapped with both hbdTSCs and hESCs but not with GOKM also in pluripotency.

We then analyzed the ChIP-seq data for the histone mark H3K4me2. As was described for the ATAC- 
compared to OSKM D3 (i.e. 5,568 peaks for 'GOKM D3' and 1,532 peaks for 'OSKM D3', Figure S4F),

while exhibiting a less pronounced difference ( 2 fold more) with hESC-specific peaks (i.e. 4,627 peaks for 'GOKM D3' and 2,395 peaks for 'OSKM D3', Figure S4G).

We then examined the relation between the hbdTSC-specific H3K4me2 peak set and the newly marked peaks in GOKM D3 and OSKM D3. We created scatterplots of the peaks which are unique to either GOKM D3 or OSKM D3, and marked the genes that are expressed in hESCs according to RNAseq

Transcription factor binding site analysis for the first group revealed that while GOKM deposit the

Finally, and in accordance with the ATAC-seq, a PCA plot generated using the most differential peaks

Taken together, our results suggest that the GOKM and OSKM transcription factor combinations each 
on the mechanism by which OSKM is capable of generating hiTSCs, albeit with a lower efficiency than

GOKM.

The reprogramming process toward hiTSCs does not induce genomic aberrations

Next, we asked whether the reprogramming process toward hiTSCs is prone to genomic aberrations.

To that end, we subjected two hbdTSC lines, hbdTSC\#2 and hbdTSC\#9, and four hiTSC clones, hiTSC\#4,

hiTSC\#11, hiTSC\#2 and hiTSC\#1, to sensitive karyotyping measurements using an Affymetrix CytoScan mosaicism in endogenous trophoblastic tissue as well ${ }^{36}$.

\section{hiTSCs exhibit an extensive DNA de/methylation rewiring toward hTSC state}

Given that the hiTSC gene expression profile is highly similar to that of hbdTSCs, we next wished to understand whether the epigenetic landscape of hiTSCs and hbdTSCs is correspondingly equivalent. 
comparatively hypomethylated DMRs showed less efficient demethylation activity. Approximately

one-third of the tiles, which display significant association to placental loci, demonstrated complete

hypomethylation in all hiTSC colonies, while the remainder of the tiles exhibited only partial

hiTSC colony, hiTSC\#11, which was derived from the PCS201 fibroblast line, clustered closer to the two

hbdTSC lines than to other hiTSC clones, which were derived from KEN (hiTSC\#1, hiTSC\#2, hiTSC\#4) or

These results suggest that demethylation is less rigorous in hiTSC reprogramming, but may also imply

the demethylation process (i.e. GM2-derived hiTSC\#16 clone that showed the lowest DNA 


\section{hiTSCs differentiate into all major trophoblast cell types with variation in EVT differentiation}

hTSCs have the ability to differentiate into multinucleated syncytiotrophoblast (STs) and extravillous

trophoblasts (EVTs) ${ }^{1}$. Thus, our next goal was to examine whether hiTSCs have the potential to

differentiate into these various trophoblast subtypes.

We performed directed differentiation into STs and EVTs using previously published protocols ${ }^{1}$. into STs similarly to hbdTSCs.

We next performed directed differentiation of hbdTSCs and hiTSCs into EVTs ${ }^{1}$. Following seeding and 400 cell attachment to the plate, cell aggregates formed in all tested clones. However, after 14 days of differentiation, the efficiency in the production of HLA-G-positive EVTs varied widely between clones (Figure 5C). While hbdTSC\#2 and hiTSC\#4 showed massive differentiation into EVTs as assessed by morphology, EVT gene expression (i.e HLA-G, MMP2, ITGA5 and ITGA1, ${ }^{1,23}$ ) and staining for the EVT markers HLA-G and ITGA5 (Figure 5C-E), hiTSC\#11 and hiTSC\#16 as well as OSKM-hiTSC\#1 demonstrated only a partial capability in producing HLA-G-positive cells (Figures 5C-F and S5C). In general, we observed two main morphologies of HLA-G-positive cells following 14 days of EVT differentiation; (i) spindle-shaped and (ii) small and migratory cells. Interestingly, while the spindleshaped cells exhibited strong HLA-G staining and weak ITGA5 expression, the small and migratory cells 409 stained strongly for both HLA-G and ITGA5 (Figure 5D-E). The appearance of multiple morphologies of EVTs in our experiments is in accordance with previous studies showing significant diversity between various EVT subtypes ${ }^{39}$.

We sought to examine whether the partial DNA demethylation observed in some hiTSC clones or reactivation of viral vectors during differentiation might contribute to the inconsistency seen during 
Aza), a known demethylation agent, for two days and performed EVT differentiation. In parallel, we

utilized a previously described non-integrating episomal reprogramming technique ${ }^{40}$, replacing the hSOX2 with hGATA3, and reprogrammed the cells into hiTSCs.

Interestingly, one of two 5-Aza treated GOKM-hiTSC clones (i.e. hiTSC\#11) restored its capability to

differentiate into EVTs (Figure 5G) and 1 out of 3 examined episomal-derived hiTSC clones showed

These results suggest that suboptimal demethylation can hinder the differentiation potential of the

Taken together, these results suggest that some hiTSC clones hold a full differentiation potential, but

\section{hiTSCs form trophoblastic lesions following subcutaneous injection into NOD/SCID mice}

When mouse TSCs/iTSCs are injected subcutaneously into nude mice, the cells differentiate into the

various trophoblast subtypes and orchestrate robust invasion and endothelial cell recruitment to form trophoblastic lesions with little differentiation and blood vessel formation ${ }^{1}$. To test whether hiTSCs 


\section{hiTSCs form functional trophoblast organoids}

Recently, two trophoblast organoid systems have been developed and described ${ }^{42,43}$. These studies demonstrated the capability of first trimester villous CTB cells to form three-dimensional structures

Thus, we next asked whether hiTSCs harbor similar potential to form trophoblastic spheres and revealed KRT7-positive organoids with proliferating cells, suggesting that undifferentiated cells were

\section{The reprogramming process into hiTSCs bypasses a pluripotent stage}

Given that OSKM can generate both hiPSCs and hiTSCs ${ }^{3,9,44}$ and since we show here that GATA3 can to generate hiTSCs. Figures S1C and S7A-E demonstrate that the OKM combination is, in principle, incapable of producing neither hiTSCs nor iPSCs as assessed by colony number and expression of hTSC and hiPSC gene markers in reprogramming plates (Figure S1C and S7A-E). Of note, very rarely and following multiple attempts, we surprisingly managed to isolate two hiPSC colonies, but not hiTSC colonies, with the OKM factors only (Figure S6B).

Additionally, since multiple components of the hTSC medium have been shown to enhance mouse 
support pluripotent cells (Figure S7D). Nevertheless, we transduced fibroblasts with the GOKM factors

and conducted reprogramming with an established hiPSC reprogramming protocol. No hiPSC colonies

emerged. We next repeated this experiment, but instead of using the hiPSC reprogramming protocol,

we began with the TSC reprogramming protocol and upon dox withdrawal we changed the medium

to hESC-supportive medium. Following three independent reprogramming experiments, we observed

the formation of only two hiPSC colonies that were positive to hESC markers and integrated all four

to induce three different cell types of the mouse preimplantation embryo depending on various

transgene levels ${ }^{11}$.

In order to further scrutinize the formation of hiPSCs during GOKM reprogramming, we sorted for

pluripotency cell-surface marker TRA-1-60 positive cells at various time points during GOKM

reprogramming, then seeded them and counted the hiPSC colonies which emerged (Figure S7G). We

chose to sort even very weakly positive cells as so not to omit any potential hiPSCs at the cost of a

higher false-positive sorting rate. Although hiPSC colonies emerged after seeding sorted cells from

OSKM reprogramming and hiPSC positive controls, no hiPSC colonies emerged in plates seeded with

cells sorted from GOKM reprogramming in various time points in the ITSC reprogramming protocol,

following GOKM reprogramming with hiPSC protocol or after switching to hESC-supportive medium after dox withdrawal following hiTSC protocol (Figure S7G).

Although the emergence of hiPSC colonies with GOKM is evidently extremely rare, it prompts further 
(Figure S7H). To confirm functional KO of SOX2 in the cells, we reprogrammed SOX2 KO fibroblasts

Taken together, these data not only indicate that SOX2, NANOG and PRDM14 expression is the hTSC state.

Placental disorders such as preeclampsia and intra-uterine growth restriction are commonly detected at late stages of pregnancy, when proliferative villous CTBs are no longer available for isolation and exploration. Thus, developing a method to reprogram differentiated cells derived from diseaseaffected placenta or cord blood into functional TSCs is of vital importance for modeling and identifying potential risk factors for placental disorders, as well as for possible future cell-based therapy for supporting implantation in cases of recurrent miscarriages.

The generation of hiTSCs from naïve hiPSCs or following OSKM pluripotency reprogramming has been recently described ${ }^{3-9}$, proposing one possible strategy of producing hiTSCs from mesenchymal cells. However, the production of hiTSCs from mesenchymal cells, independently of pluripotency or

The direct conversion of fibroblasts into hiTSCs provides multiple advantages, both for basic research 
are necessary for the induction of the hTSC state, while pluripotency-dependent protocols (i.e. OSKM

Here, we demonstrate that transient expression of GATA3, OCT4, KLF4 and MYC (GOKM) is capable of trophoblast lineage ${ }^{20}$, our work confirms that this role is independent of its known function as a master regulator of pluripotency.

We show that GOKM target the chromatin differently than OSKM and that GOKM reprogramming is

Methylation analysis revealed that the overwhelming majority of hbdTSC-specific methylated regions, 
ESC-TSC transdifferentiation are demethylated properly in the reprogrammed hiTSCs, similarly to the mouse ${ }^{12,23}$.

It is important to note that appropriate rewiring of the methylation landscape during reprogramming

Given recent literature showing the capacity to derive hiTSCs from naïve pluripotency conditions and reprogramming, and following the issues mentioned above regarding pluripotency and the hTSC state, it was important to confirm that GOKM hiTSCs do not rely on obtaining a transient pluripotent state. By knocking out SOX2 or NANOG/PRDM14 in fibroblasts, we show that not only is pluripotency not required for the formation of hiTSCs, but rather it likely hinders hiTSC production, as a greater number of colonies emerged in the KO fibroblast lines compared to WT fibroblasts.

Functional experiments validated hiTSC identity and demonstrated full developmental potential as 600 assessed by capability to differentiate into STs and EVTs, form trophoblastic lesions in NOD/SCID mice and develop organoids in matrigel. We believe that the variations in EVT differentiation noted between different hiTSC colonies may be a result of the variation observed in the DNA methylation landscape of the cells. In support of this assumption, 5-Aza treatment facilitated EVT differentiation in some EVT-refractory treated clones.

Overall, we describe a system to produce fully functional hiTSCs from mesenchymal cells originating

\section{ACKNOWLEDGMENTS}

Y.B. is supported by a gift from the Morningstar Foundation and Edward \& Millie Carew-Shaw 
Howard Hughes Medical Institute International Research Scholar (HHMI, \#55008727). A.R. is

\section{AUTHOR CONTRIBUTIONS}

Y.B. conceived the study and prepared the figures. Y.B. and M.N. wrote the manuscript. M.N, S.S. and

Y.B. designed the experiments. M.N. performed the following experiments: hiTSC and hiPSC

ATAC-seq and ChIP-seq data. V.Z. cloned the various transcription factors and initiated the

reprogramming experiments toward hiTSCS. S.S. prepared the RNA libraries, performed

immunohistochemistry, ELISA, qPCR for C19MC miRNAs and subcutaneously injected cells into

NOD/SCID mice. R.L., N.D. and D.O. ran qPCRs and validated SOX2 KO. K.M. injected hiTSCs. M.J.

and analyzed the RRBS data. M.R. performed part of the organoid experiments and qPCR. H.Y. 
All RNA-seq, RRBS, ATAC-seq and ChIP-seq data were deposited in the Gene Expression Omnibus

database

(GEO)

under

accession

number

GSE182017

638

(https://www.ncbi.nlm.nih.gov/geo/query/acc.cgi?acc=GSE182017). The authors declare no

competing financial interests. Correspondence and requests for materials should be addressed to Y.B.

(yossibug@ekmd.huji.ac.il).

METHODS

Derivation of human trophoblast stem cells from human blastocysts and human fibroblasts from

skin biopsy and cell lines. The establishment and use of hbdTSC lines or hESC lines from PGD-derived

embryos was performed in compliance with the protocols approved by the Ethic Committee of Shaare

Zedek Medical Center (IRB 87/07). Embryo donations were carried out under the strict regulation of

the National ethic committee (Israel health ministry) and NIH and ISSCR guidelines. In order to

Molecular Cloning and hiTSC and hiPSC reprogramming. All dox-inducible factors were generated by 
encoding puromycin resistance and M2rtTA, and subsequently selected with $2 \mu \mathrm{g} / \mathrm{ml}$ puromycin for reprogramming medium (BRM) consisting of fresh DMEM containing $10 \% \mathrm{FBS}, 1 \% \mathrm{~L}$-glutamine and $1 \%$ penicillin-streptomycin.

For hiTSC reprogramming, six hours after medium replacement $2 \mu \mathrm{g} / \mathrm{ml}$ doxycycline (dox) was added colonies emerged.

For hiPSC reprogramming, six hours after medium replacement $2 \mu \mathrm{g} / \mathrm{ml}$ doxycycline (dox) was added medium was replaced with $50 \%$ BRM and $50 \%$ human embryonic stem cell (hES) medium comprised of Knockout DMEM containing 15\% KnockOut serum replacement, $0.1 \mathrm{mM}$ 2-mercaptoethanol, 1\% L-

Generation of non-integrating episomal-derived hiTSCs. Episomal vectors: pCLXE-hOCT4-shp53, 
reprogramming medium (BRM) consisting of fresh DMEM containing $10 \% \mathrm{FBS}, 1 \%$ L-glutamine, and $1 \%$ penicillin-streptomycin. For hiTSC reprogramming, the fibroblasts were cultured in BRM for 10 days, and then the medium was exchanged to hTSC medium (Okae et al., 2018) for another 14 days. Plates were then screened for primary hiTSC colonies. Each colony was isolated by manually picking up colonies with a pipette, trypsinized with TrypLE (Gibco), and plated in a separate well on feeder cells in hTSC medium. The cells were passaged several times until stable proliferative hiTSC colonies emerged.

Quantitative PCR (qPCR) for mRNA expression and analysis of genomic integration of transgenes.

For analysis of mRNA expression using qPCR, total RNA was isolated using the Macherey-Nagel kit (Ornat). 500-1000ng of total RNA was reverse transcribed using iScript cDNA Synthesis kit (Bio-Rad). Quantitative PCR analysis was performed in duplicates using $1 / 100$ of the reverse transcription reaction in a StepOnePlus (Applied Biosystems) with SYBR green Fast qPCR Mix (Applied Biosystems). Specific primers were designed for the different genes (see Table 1). All quantitative real-time PCR deviation of two duplicate runs.

For analysis of integration of transgenes into genomic DNA using $\mathrm{qPCR}$, genomic DNA was isolated by incubating trypsinized cell pellets in lysis buffer consisting of $100 \mathrm{mM}$ Tris pH8, $5 \mathrm{mM}$ EDTA, $0.2 \%$ SDS and $200 \mathrm{mM} \mathrm{NaCl}$ overnight with $400 \mu \mathrm{g} / \mathrm{ml}$ proteinase $\mathrm{K}$ (Axxora) at $37^{\circ} \mathrm{C}$ for one hour followed by incubation at $55^{\circ} \mathrm{C}$ for one hour. Then, genomic DNA was precipitated with isopropanol, washed with $70 \%$ ethanol and resuspended in ultra-pure water (BI). Forward primers for the end of the last exon of cloned genes were used in conjunction with reverse primers for the FUW-tetO vector at the region immediately downstream of the cloned gene (see Table 1). Results were normalized to an intronic region of the GAPDH gene and presented as a mean \pm standard deviation of two duplicate runs.

\section{QRT-PCR of MiRNA}

Cells of four hiTSC colonies, hbdTSC, hESCs and breast cancer cell line MDA-MB-231 were lysed and total RNA was isolated using the Macherey-Nagel kit (Ornat). To quantify C19MC miRNAs, we adapted 
Immunostaining of PFA-fixated cells and flow cytometry. Cells were fixed in $4 \%$ paraformaldehyde

(in PBS) for 20 minutes, then rinsed 3 times with PBS and blocked for 1 hour with PBS containing $0.1 \%$

triton X-100 and 5\%FBS. The cells were incubated overnight with primary antibodies (1:200-1:500

dilution) in 4C. The antibodies are: anti-KRT7 (Abcam, ab215855), anti-GATA3 (Abcam, ab106625),

anti-GATA2 (Abcam, ab173817), anti-TFAP2C (Santa Cruz Biotechnologies, sc-12762), anti-KRT18

(Santa Cruz Biotechnologies, sc-51582), anti-CDH1 (Santa Cruz Biotechnologies, sc-7870), anti-VIM

(Cell Signaling Technology, \#5741), anti-SDC1 (Abcam, ab128936), anti-CSH1 (Abcam, ab15554), anti-

10 minutes before end of incubation. Negative control included incubation with secondary antibody

without primary.

For flow cytometry analysis of HLA class I and TRA-1-60 expression, cells were trypsinized and blocked

Abcam, ab22432) or anti-TRA-1-60 (1:300, Abcam, ab16288) for 1 hour. Cells were then washed with

RNA and RRBS library preparation and sequencing and karyotype analysis. For RNAseq, total RNA

For RRBS, DNA was isolated from samples and incubated in lysis buffer $(25 \mathrm{mM}$ Tris- $\mathrm{HCl}$ at pH8, 2mM 
Chromatin immunoprecipitation (ChIP). Chromatin immunoprecipitation (ChIP) assay was performed

as previously described ${ }^{53}$. Briefly, cells from two biological replicates per line were fixed for $10 \mathrm{~min}$ at

RT with a final formaldehyde concentration of $0.8 \%$. Formaldehyde was quenched with glycine at a

final concentration of $125 \mathrm{mM}$. The cells were then lysed with lysis buffer $(100 \mathrm{mM}$ Tris- $\mathrm{HCl}, 300 \mathrm{mM}$

$\mathrm{NaCl}, 2 \%$ Triton X-100, $0.2 \% \mathrm{v}$ sodium deoxycholate and 10mM Cacl2) supplemented with EDTA-free EGTA. The fragmented chromatin was added to pre-bounded Dynabeads (A and G mix, Invitrogen, 10004D/ 10002D) using H3K4me2 antibody (Millipore, 07-030) at $2 \mu \mathrm{g}$ per reaction. Samples were 780 then washed twice with RIPA buffer, twice with RIPA high salt buffer ( $\mathrm{NaCl} 360 \mathrm{mM})$, twice with LiCl 781 wash buffer (10mM Tris-Hcl, $250 \mathrm{mM} \mathrm{LiCl,} 0.5 \%$ DOC, $1 \mathrm{mM}$ EDTA, 0.5\% IGEPAL) and twice with $10 \mathrm{mM}$ 782

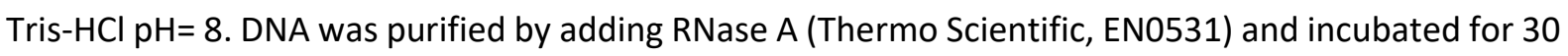
783 $\min$ at $37^{\circ} \mathrm{C}$ and then with Proteinase K (Invitrogen, 25530049) for $2 \mathrm{~h}$. The DNA was eluted by adding 784 $2 X$ concentrated elution buffer $(10 \mathrm{mM}$ Tris $-\mathrm{HCl}, 300 \mathrm{mM} \mathrm{NaCl}, 1 \%$ SDS, $2 \mathrm{mM}$ EDTA) and reverse 785 crosslinked overnight at $65^{\circ} \mathrm{C}$. The DNA was then extracted using AMPure XP beads (Beckman Coulter 786 Genomics, A63881). ChIP sample libraries were prepared according to Illumina Genomic DNA 787 protocol.

ATAC libraries and Sequencing. ATAC-Seq library preparation was performed as previously described Streptomycin, 0.3\% BSA, 1\% ITS supplement, $2.5 \mu \mathrm{M}$ Y27632, $2 \mu \mathrm{M}$ forskolin, and $4 \% \mathrm{KSR}$, as described 800

${ }^{1}$. Cells were collected at day 2 and 6 for analysis of mRNA expression using qPCR as described above. 801 Cells were also seeded on 12-well plates at a density of approximately $10^{5}$ cells per plate, cultured 802 similarly and fixated in 4\% PFA for immunostaining as described above. 
DMEM/F12 supplemented with 0.1mM 2-mercaptoethanol, 0.5\% Penicillin-Streptomycin, 0.3\% BSA,

Replacement, as described by ${ }^{1}$. Matrigel was added to a final concentration of $2 \%$. At day 3 , the medium was replaced with the EVT medium without NRG1, and Matrigel was added to a final concentration of $0.5 \%$. Medium was replaced every other day, and cells were collected at day 7 and

Formation of trophoblast organoids with bdTSCs and hiTSCs. Similar to as described in ${ }^{42}$, bdTSCs and

Immunostaining of bdTSC and hiTSC trophoblast organoids. Organoid-containing Matrigel domes were fixated in 4\% PFA overnight. Then, domes were washed with PBS for 15 minutes twice. Domes were submerged in blocking solution containing $3 \%$ bovine serum albumin (BSA), $5 \%$ fetal bovine serum (FBS), $0.1 \%$ Triton $\mathrm{X}-100$ in PBS, at $4 \mathrm{C}$ overnight. Then, tissues were incubated with primary 
Engraftment of hiTSCs into NOD/SCID mice and immunohistochemistry (IHC). For each lesion, approximately $4 \times 10^{6}$ were trypsinized with TrypLE, washed twice in PBS, resuspended in $150 \mu \mathrm{l}$ of a

The joint ethics committee (IACUC) of the Hebrew University and Hadassah Medical Center approved

Lesions were collected nine days after injection, dissected, fixed in $4 \%$ paraformaldehyde overnight,

For IHC, slides were deparaffinized in xylene and rehydrated in a decreasing ethanol gradient. Antigen

After a short incubation in 3\% hydrogen peroxide, sections were incubated overnight in CAS-block

hCG detection in the blood of hiTSC-injected mice. For testing presence of hCG in NOD/SCID mice,

Quantification of human chorionic gonadotropin (hCG) hormone levels were determined by ELISA kit

ELF5 bisulfite sequencing. ELF5 bisulfite sequencing was performed as previously published ${ }^{23}$. DNA 
NANOG) or hygromycin B (PRDM14) resistance (Addgene plasmids \#52961 and \#98291 respectively)

using $\mathrm{BsmBI}$ restriction enzyme, as described in ${ }^{47}$. These were used to infect HFFs (KEN), which were

$2 \mu \mathrm{g} / \mathrm{ml}$ puromycin for 3-5 days (SOX2-KO), or underwent double selection with both $2 \mu \mathrm{g} / \mathrm{ml}$

RNA-Seq analysis. For analysis of RNA-seq data, raw reads (FastQ files) were quality-trimmed using promoters in transcription factor binding sites.

DNA Methylation analysis. For the analysis of RRBS data, raw reads (FastQ files) were quality-trimmed 
computed based on $100 \mathrm{bp}$ tiles. Differentially methylated regions (DMR) table obtained from

Methylkit (v 1.14.2, DOI: 10.18129/B9.bioc.methylKit) processing of the BAM files yielded by BSMAP

alignment. Each table represents the following parameters: Chromosome (chr), start and end coordinates of the methylated region (start, end), strand location (strand), probability value "pvalue",

For the analysis of direct amplification and sequencing of the ELF5 promoter a FATSTA file that

ATAC-Seq and ChIP-Seq analysis. For analysis of the accessibility and activity data, raw reads (FastQ files) were quality-trimmed using Trim Galore (v0.6.5, default parameters) and aligned to the human 
Figures

Figure 1

A

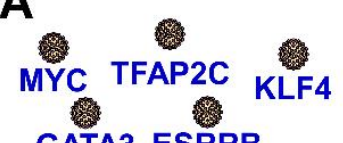

GATA3 ESRRB

Reprogramming protocol

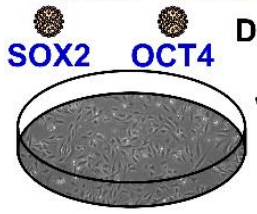

Fibroblasts

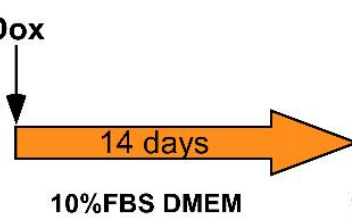

$10 \%$ FBS DMEM

B

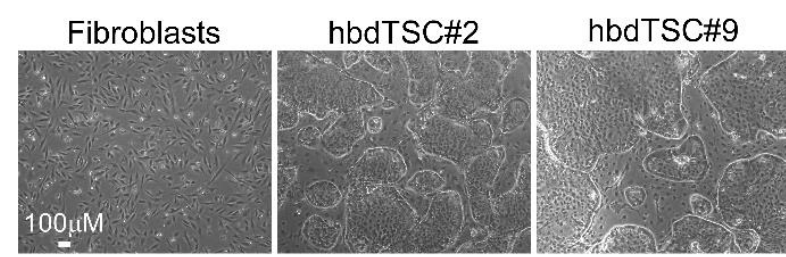

C

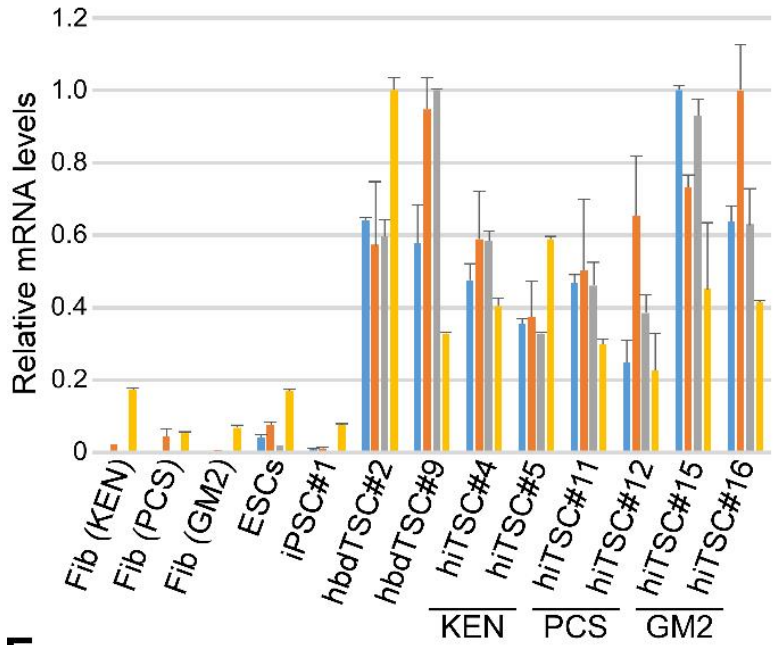

E

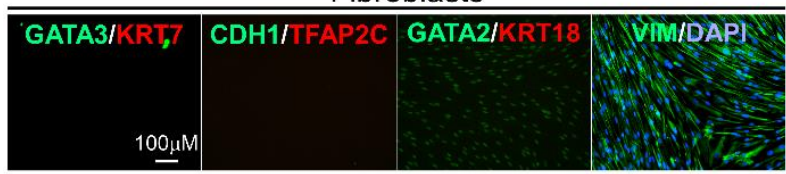

hiTSC\#4

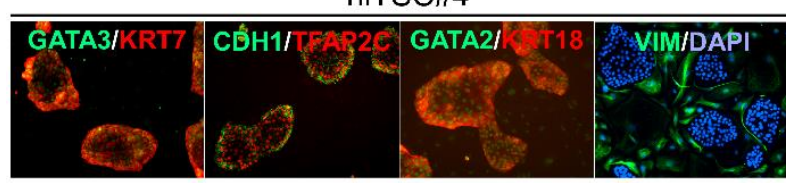

hiTSC\#16

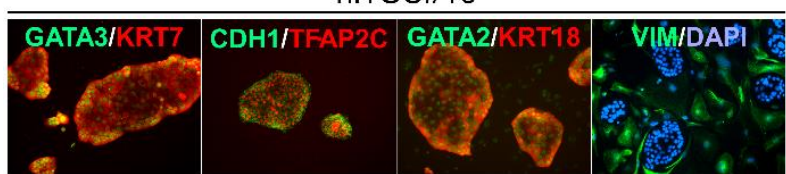

Dox-independent GOKM-hiTSC colonies
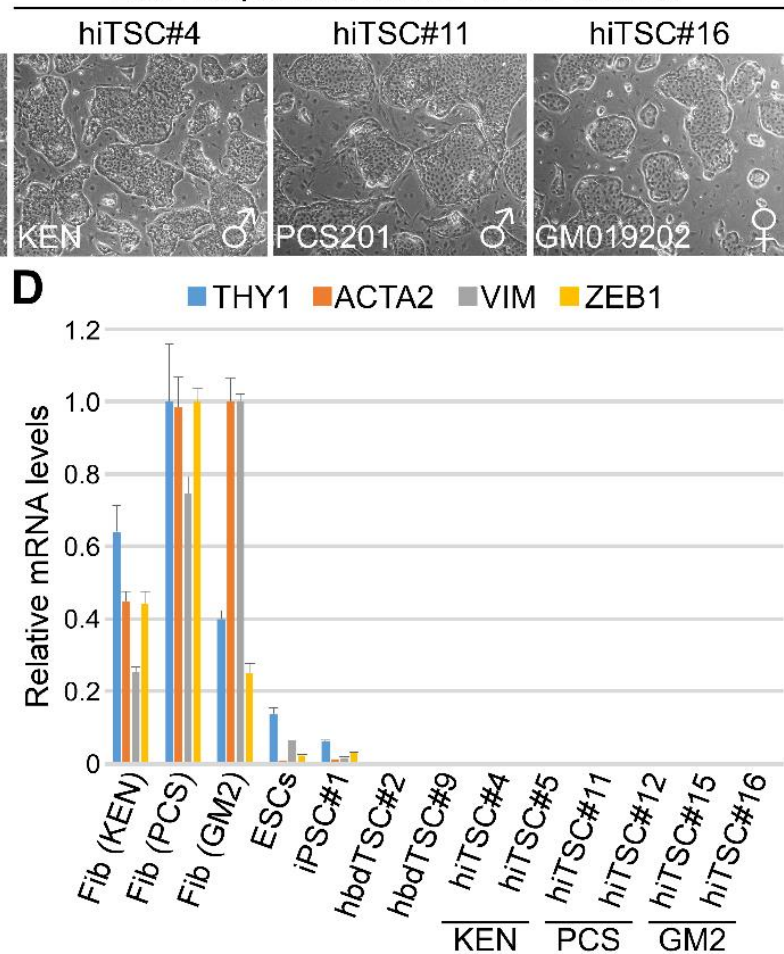

hbdTSC\#2

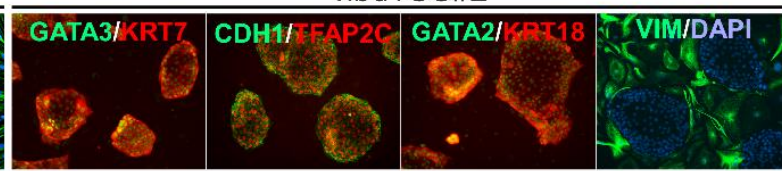

hiTSC\#11

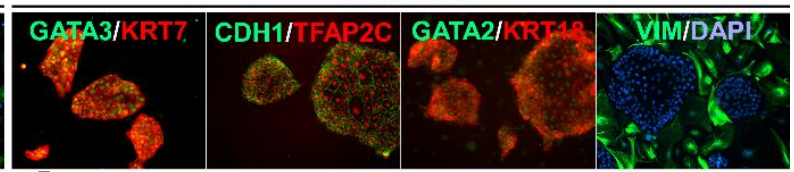

$F$

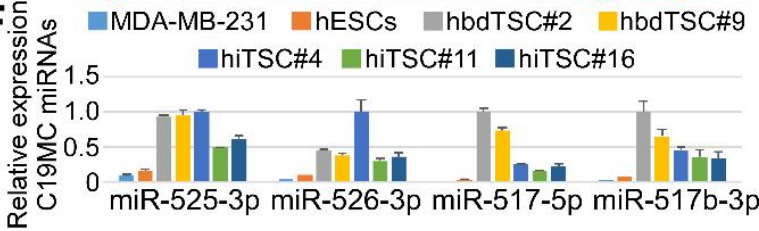


bioRxiv preprint doi: https://doi.org/10.1101/2021.11.10.468044; this version posted November 11, 2021. The copyright holder for this

preprint (which was not certified by peer review) is the author/funder, who has granted bioRxiv a license to display the preprint in perpetuity. It is made available under aCC-BY-NC-ND 4.0 International license.

Figure 2

A

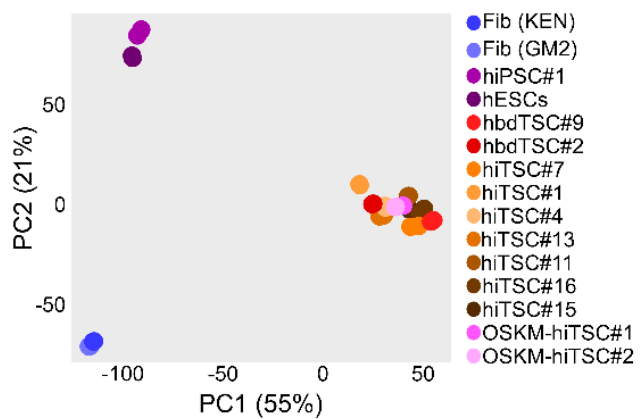

B

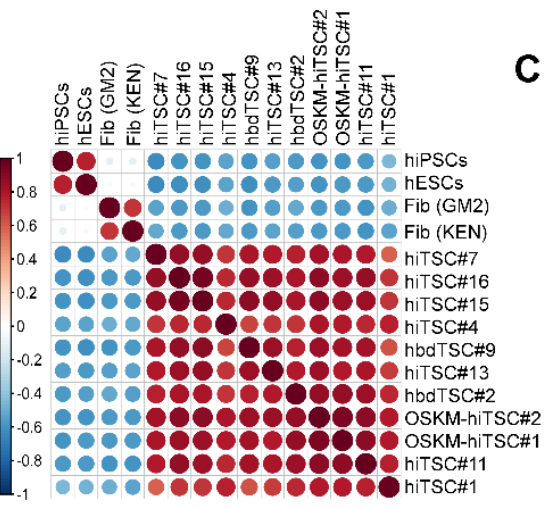

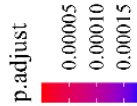

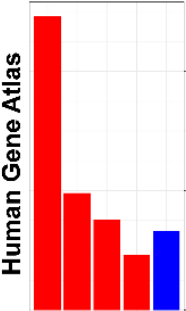

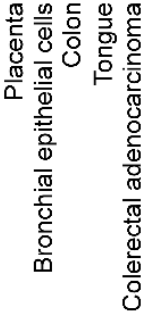

D

E

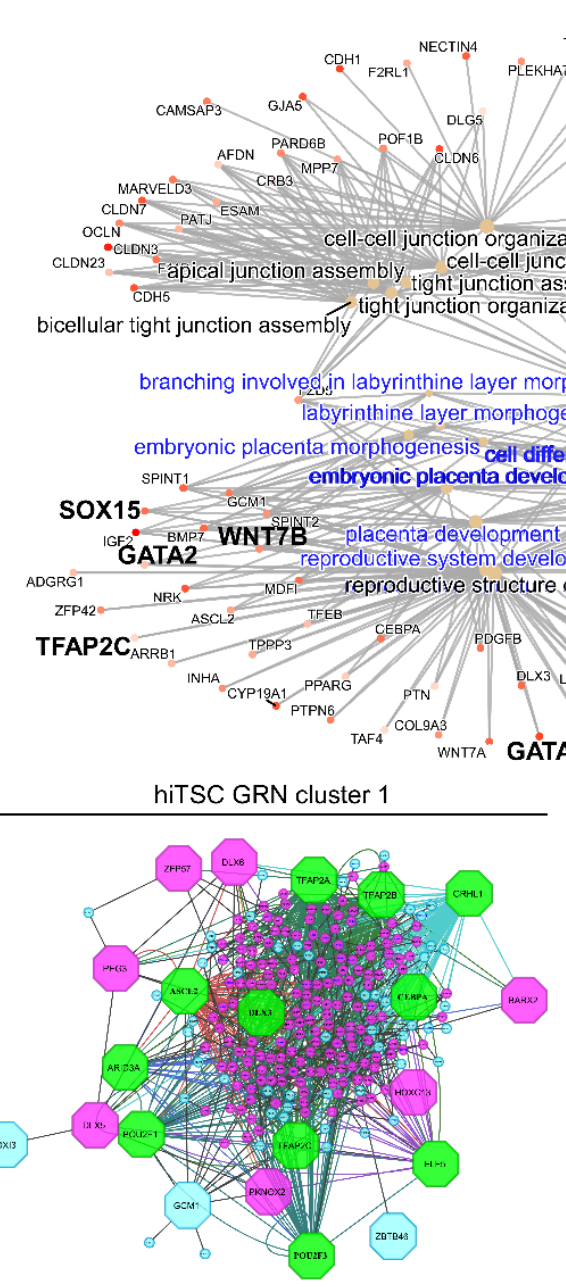

$\mathbf{F}$
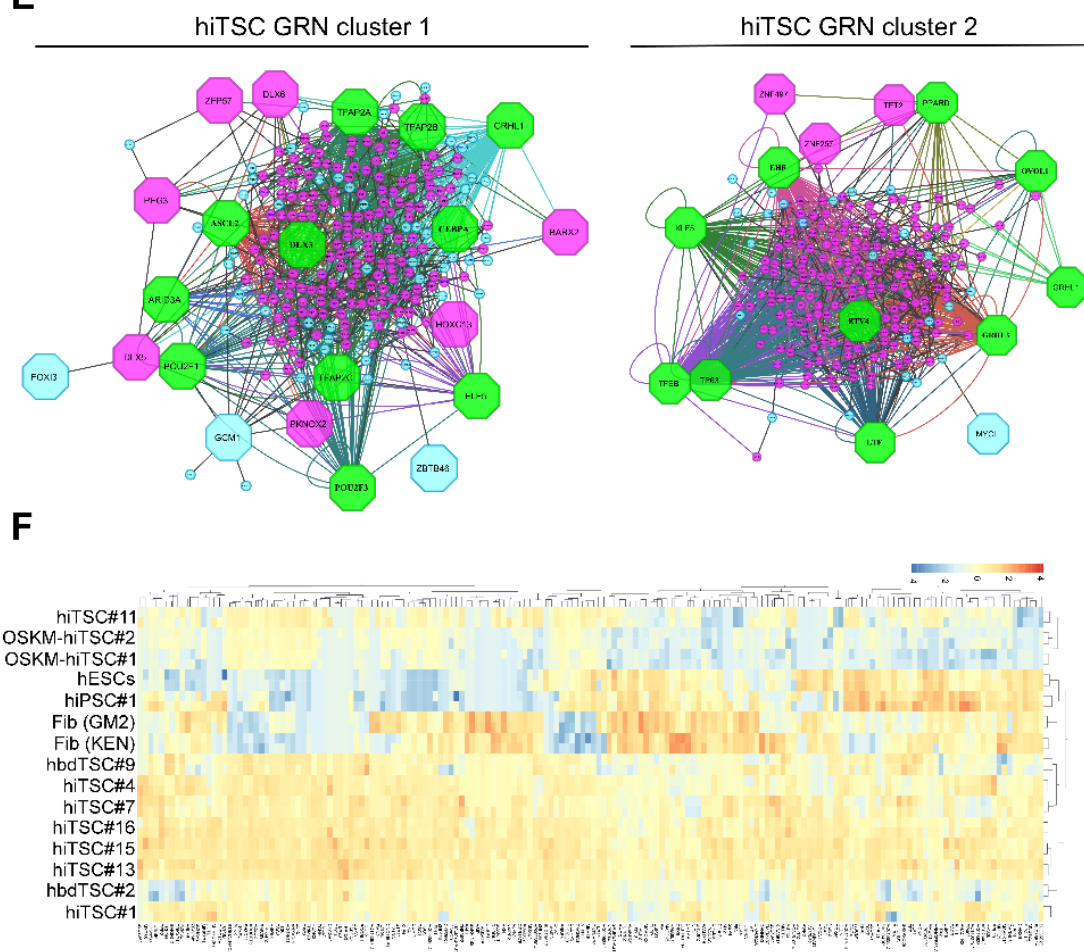

hiTSC GRN cluster 4

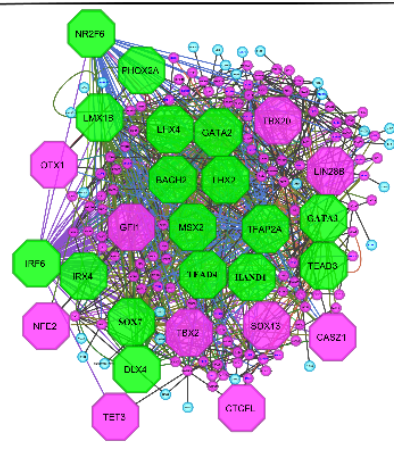

G

Placenta
CD14+ Monocytes
CD33+ Myeloid
Pons
Cerebellum Peduncles
Fetal lung
Whole blood
Leukemia
Lymphoma
Seminiferous tubule

Signal transduction through IL-1R PV-178E-4 Structual pathway of IL-1 Sphingolipid pathway

Heart development

-cell antigen receptor signaling

Simplified Depiction of MYD88

Mammary gland deveph

Mammary gland development 
Figure 2. RNA-seq analysis indicates that GOKM-derived hiTSCs exhibit a transcriptome that is highly

similar to that of hbdTSCs. (A-B) Plots based on RNA-seq data portraying comparisons of whole

transcriptome of two biological duplicates of two lines of parental fibroblasts (KEN and GM2), two

pluripotent stem cell clones, hESCs and hiPSCs, two hbdTSCs lines, hbdTSC\#2 and hbdTSC\#9, seven

GOKM-derived hiTSC clones, hiTSC\#1, hiTSC\#4, hiTSC\#7, hiTSC\#11, hiTSC\#13, hiTSC\#15 and hiTSC\#16,

and two OSKM-derived hiTSC clones, OSKM-hiTSC\#1 and OSKM-hiTSC\#2. Principal component

analysis (PCA) plot (A) constructed using the top 2000 differentially expressed genes, and correlation

heatmap (B) of bulk RNA displaying the transcriptional similarity between hbdTSCs and hiTSCs and

their dissimilarity from PSCs (ESCs and iPSCs) and fibroblasts (KEN and GM2). (C) Bar graph showing

the highest enriched GO terms for the top 1000 most differentially expressed genes under the Human

Gene Atlas category. (D) Gene concept network for top 1000 upregulated genes in hiTSCs versus

fibroblasts. Genes are represented with a heat colorimetric scale showing the fold change in their

expression (red for the highest fold change) and linked to up-regulated GO-terms. A significant

enrichment for GO terms relevant to placenta and embryonic placenta morphogenesis and

development (according to the Human Gene Atlas, marked by blue) is shown. (E) Network analysis for

top 2000 upregulated genes in hiTSCs versus fibroblasts. Protein-protein interaction network was

analyzed with STRING (http://www.string-db.org). The MCODE plugin tool in Cytoscape was used for

further analysis of densely connected genes. For each subnetwork we used iRegulon plugin tool in

Cytoscape to systematically analyze the composition of the gene promoters in transcription factor

binding sites. (F) Heatmap and hierarchical clustering of 172 genes that were found to be differentially expressed in OSKM-derived hiTSCS when compared to hbdTSCs and GOKM-derived hiTSC clones. 
bioRxiv preprint doi: https://doi.org/10.1101/2021.11.10.468044; this version posted November 11, 2021. The copyright holder for this

preprint (which was not certified by peer review) is the author/funder, who has granted bioRxiv a license to display the preprint in perpetuity. It is made available under aCC-BY-NC-ND 4.0 International license.

Figure 3

ATAC-seq $(368,236$ peaks $)$

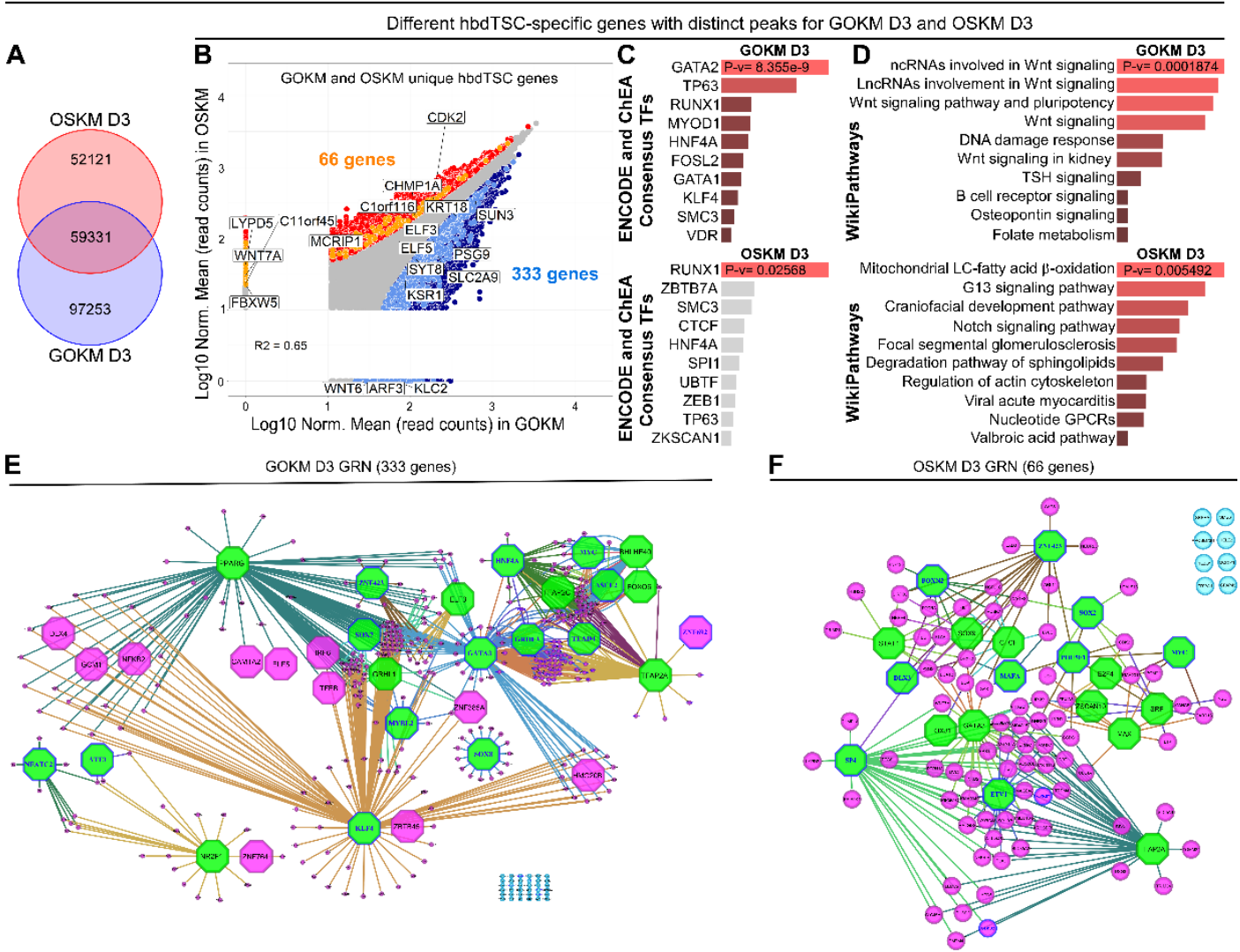

Similar hbdTSC-specific genes with distinct peaks for GOKM D3 and OSKM D3
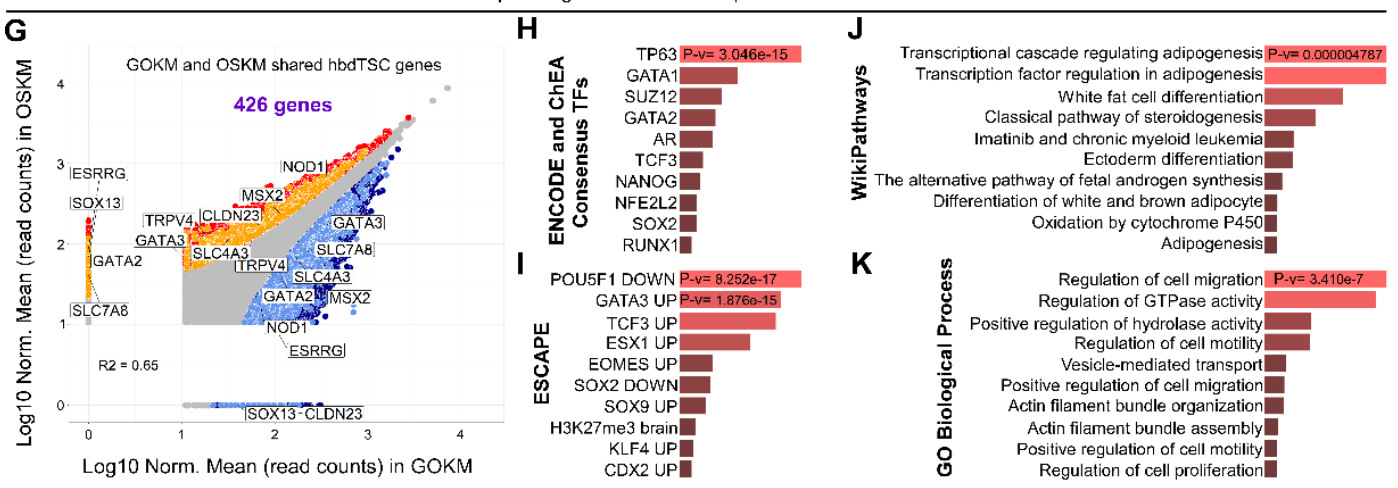

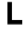

M

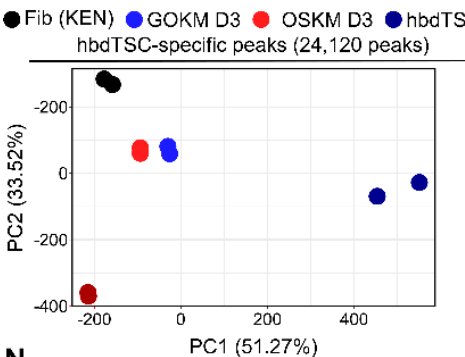

$\mathbf{N}$

10,845 GOKM-specific ATAC-seq peaks overlapping with hbdTSC-specific peaks

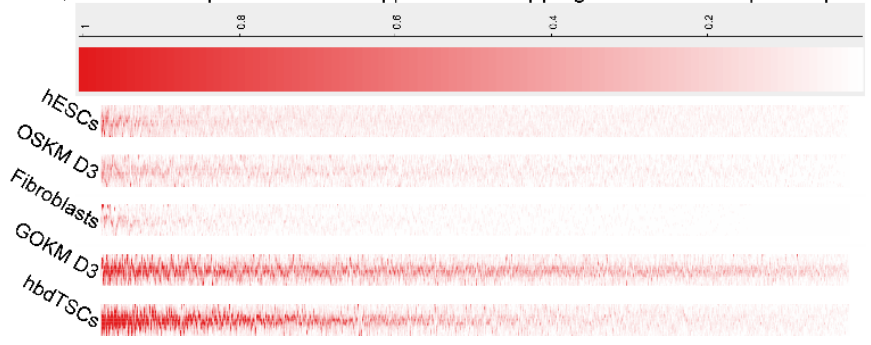

ELF5 gene

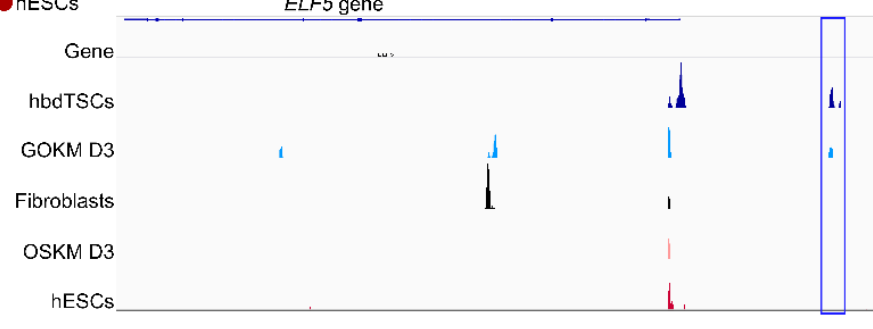

O 1,739 OSKM-specific ATAC-seq peaks overlapping with hbdTSC-specific peaks

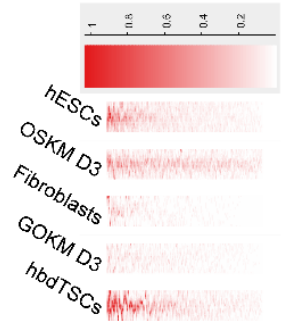


Figure 3. GOKM and OSKM each occupy the genome in a distinct manner and activate different

placenta-related loci and pathways. To assess chromatin accessibility and activity of GOKM or OSKM

early reprogrammable cells, GOKM or OSKM-transduced fibroblasts were exposed to dox for 72 hours

state are labeled with orange. (C-D) Bar graphs showing the most enriched GO terms for 333 genes

from (B) that were found to overlap between hbdTSC-specific genes and peaks that are associated

with these genes in GOKM D3, and 66 genes from (B) that were found to overlap between hbdTSC- 
bioRxiv preprint doi: https://doi org/10.1101/2021.11.10.468044; this version posted November 11,2021 . The copyright holder for this preprint (which was not certified by peer review) is the author/funder, who has granted bioRxiv a license to display the preprint in perpetuity. It is made available under aCC-BY-NC-ND 4.0 International license.

peaks but not with OSKM (FDR< 0.05 and LFC $>1.5$ ). (0) Heatmap of 1,739 open ATAC-seq OSKM- 
bioRxiv preprint doi: https://doi.org/10.1101/2021.11.10.468044 - this version posted November 11, 2021. The copyright holder for this

preprint (which was not certified by peer review) is the author/funder, who has granted bioRxiv a license to display the preprint in perpetuity. It is made available under aCC-BY-NC-ND 4.0 International license.

\section{Figure 4}

\section{A}

\section{De novo methylated regions (20333 DMRs)}
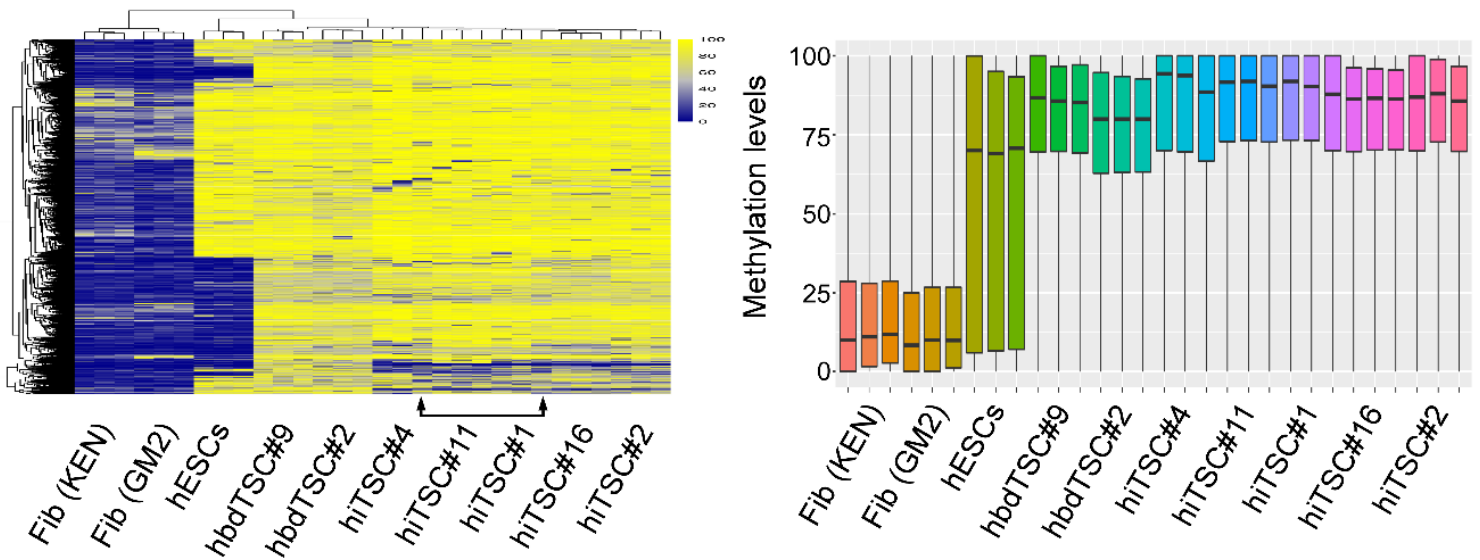

B

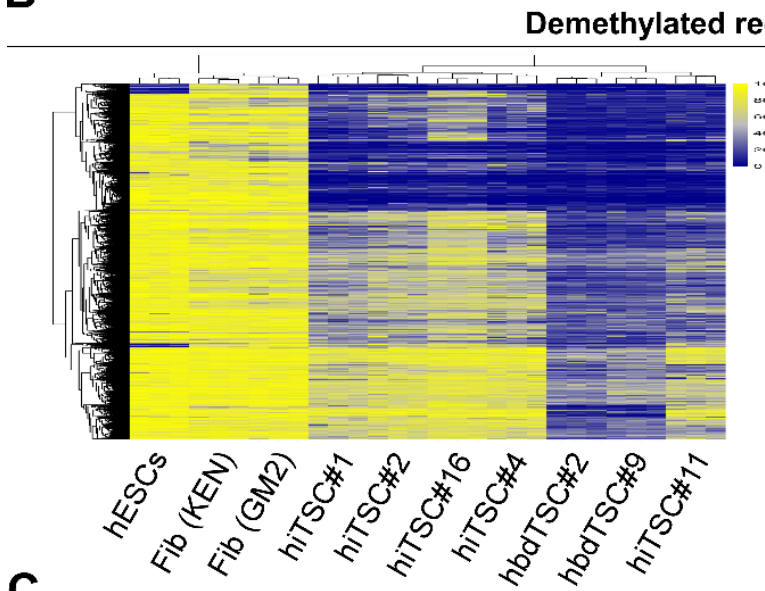

C

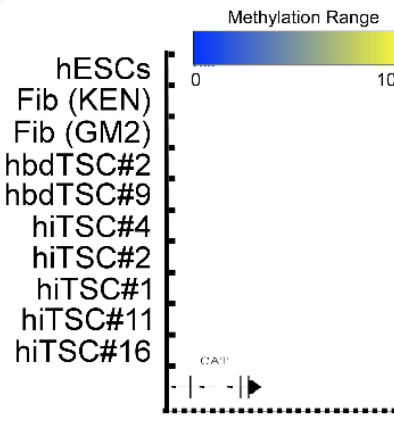

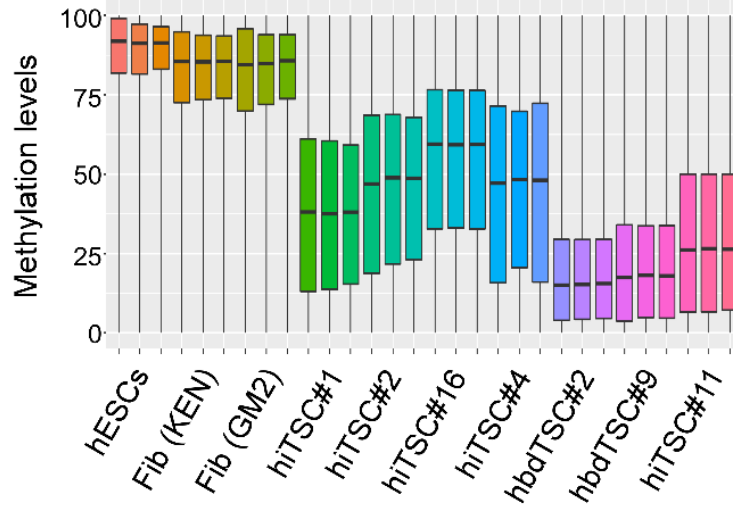

ELF5 locus

\begin{tabular}{|c|c|c|c|}
\hline $65 \%$ & $81 \%$ & $89 \%$ & $90 \%$ \\
\hline $64 \%$ & $73 \%$ & $68 \%$ & $68 \%$ \\
\hline $69 \%$ & $71 \%$ & $85 \%$ & $65 \%$ \\
\hline $43 \%$ & $30 \%$ & $21 \%$ & $62 \%$ \\
\hline $39 \%$ & $54 \%$ & $19 \%$ & $28 \%$ \\
\hline $50 \%$ & $90 \%$ & $18 \%$ & $41 \%$ \\
\hline $49 \%$ & $41 \%$ & $40 \%$ & $34 \%$ \\
\hline $49 \%$ & $60 \%$ & $41 \%$ & $46 \%$ \\
\hline $42 \%$ & $41 \%$ & $27 \%$ & $0 \%$ \\
\hline $50 \%$ & $34 \%$ & $30 \%$ & $18 \%$ \\
\hline
\end{tabular}

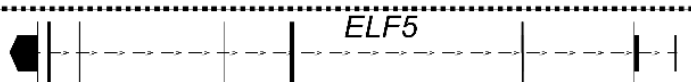

E

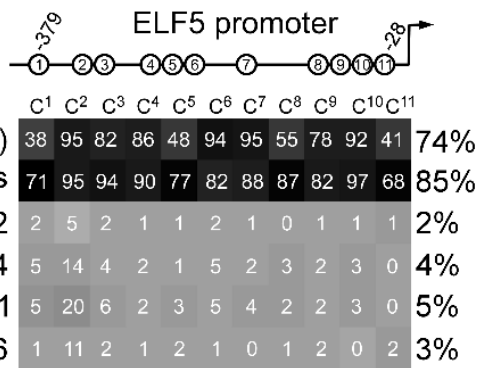

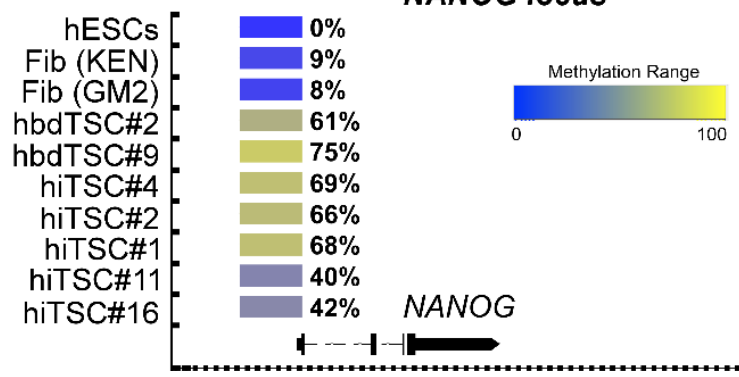


Figure 4. RRBS analysis demonstrates trophoblast-specific changes in methylation in hiTSCs. DNA

Methylation analysis of three biological replicates of fibroblasts (KEN and GM2), hESCs, two hbdTSCs quartiles, respectively), and the band near the middle of the box is the 50th percentile (the median). methylation levels of five tiles that reside within the ELF5 locus in hESCs, fibroblast (KEN and GM2), hbdTSCs (hbdTSC\#2 and hbdTSC\#9), and five hiTSC clones, as assessed by RRBS. (D) Graph depicting average methylation levels of 11 CG within the proximal ELF5 promoter, in the indicated samples, as 
bioRxiv preprint doi: https://doi.org/10.1101/2021.11.10.468044; this version posted November 11, 2021. The copyright holder for this

preprint (which was not certified by peer review) is the author/funder, who has granted bioRxiv a license to display the preprint in perpetuity. It is made available under aCC-BY-NC-ND 4.0 International license.

Figure 5

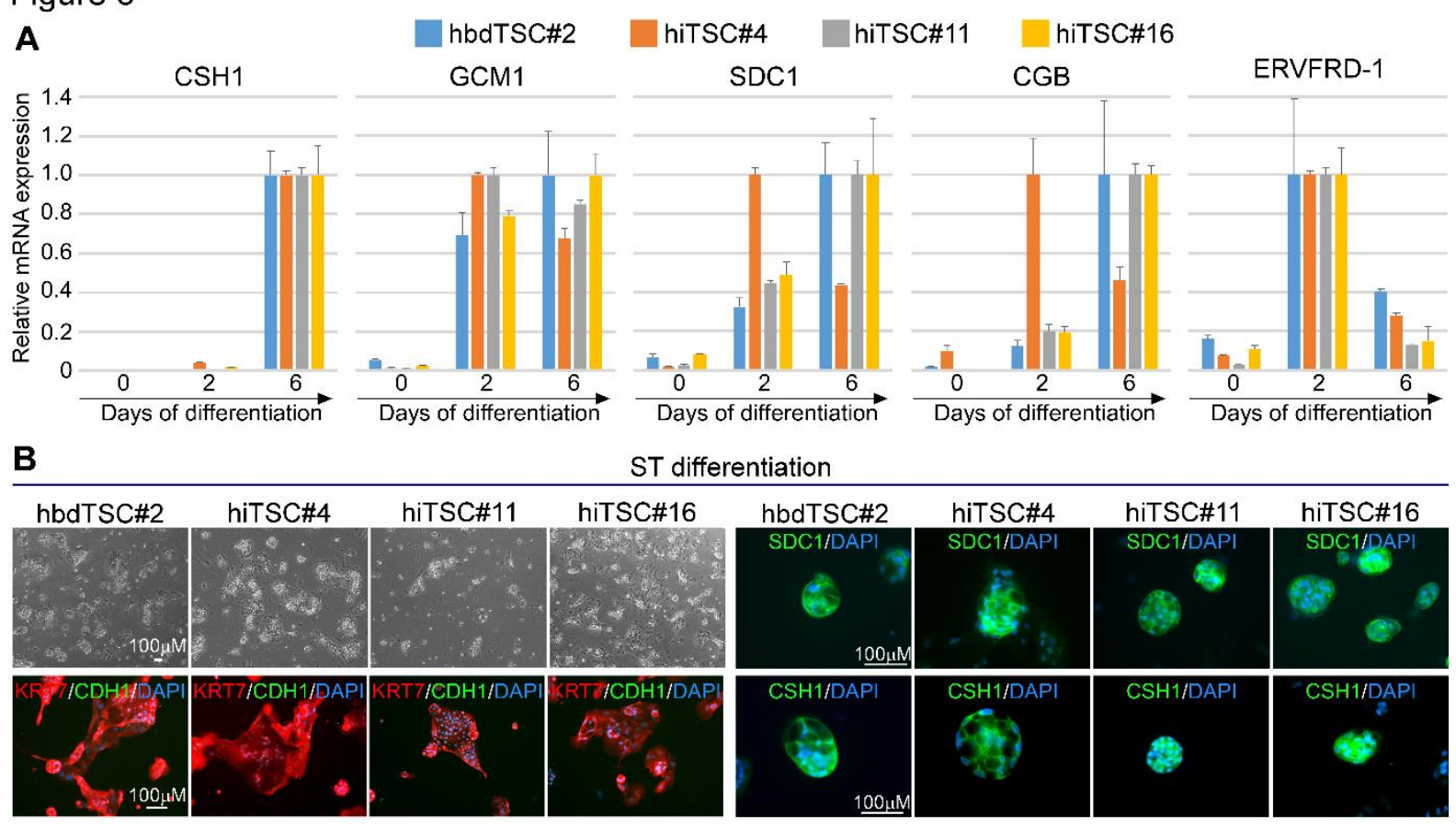

C hbdTSC\#2 hiTSC\#4 hiTSC\#11 hiTSC\#16 HLA-G MMP2 ITGA1 ITGA5

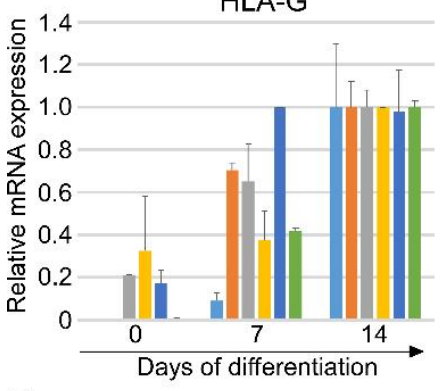

D

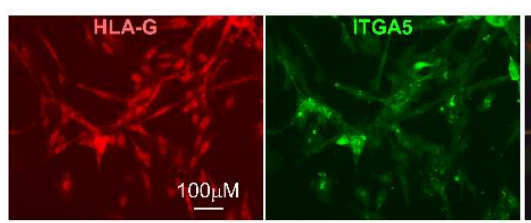

$\mathbf{F}$

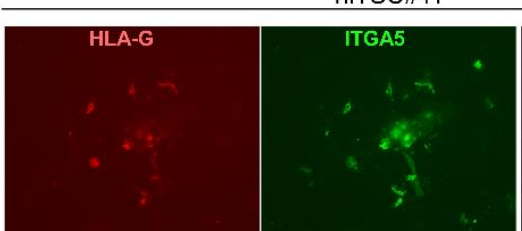

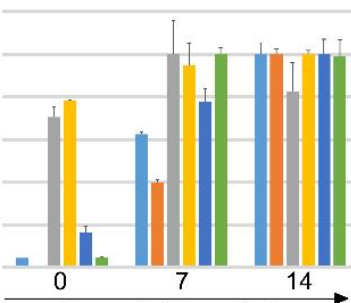

14.
E

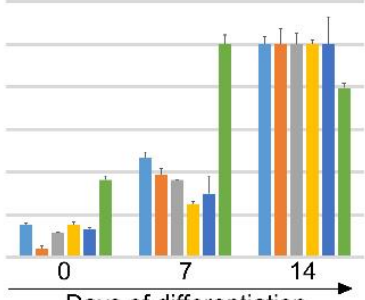

hiTSC\#4
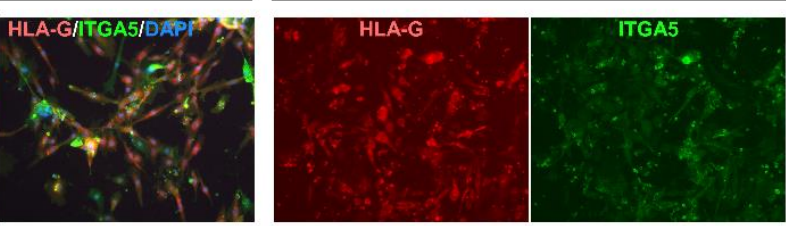

G

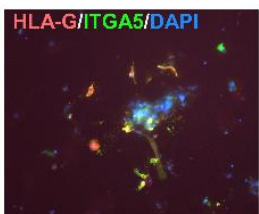

5-Aza-treated hiTSC\#11

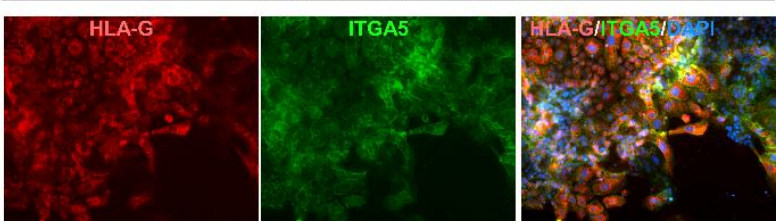


Figure 5. hiTSCs differentiate into multinucleated ST and EVT cells. hbdTSC\#2, hiTSC\#4, hiTSC\#11 and mRNA levels of ST-specific markers CSH1, GCM1, SDC1, CGB and ERVFRD-1, for the indicated samples, 
bioRxiv preprint doi: https://doi.org/10.1101/2021.11.10.468044; this version posted November 11, 2021. The copyright holder for this preprint (which was not certified by peer review) is the author/funder, who has granted bioRxiv a license to display the preprint in perpetuity. It is made available under aCC-BY-NC-ND 4.0 International license.

Figure 6
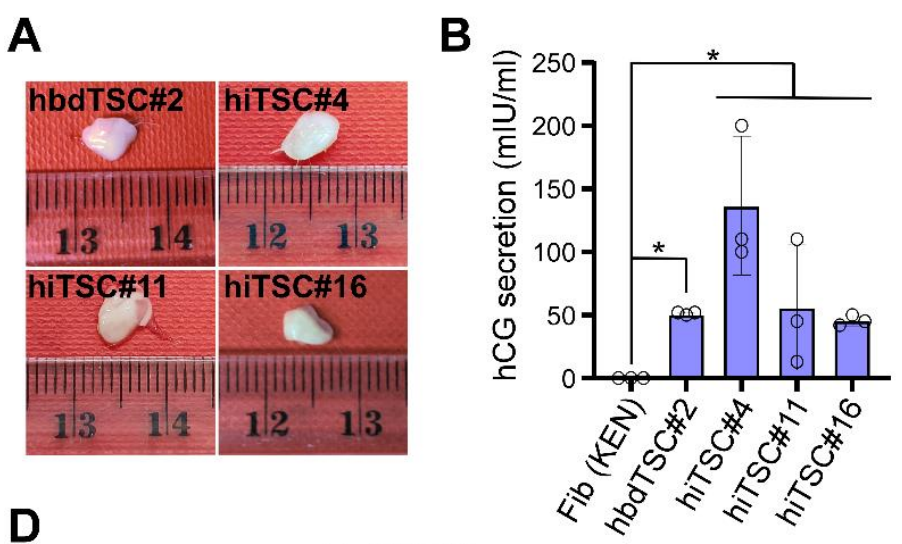

Trophospheres formation
during reprogramming

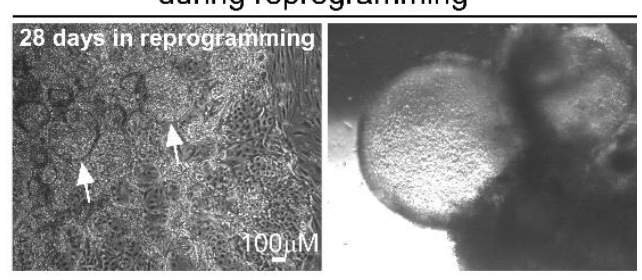

D

hbdTSC\#2

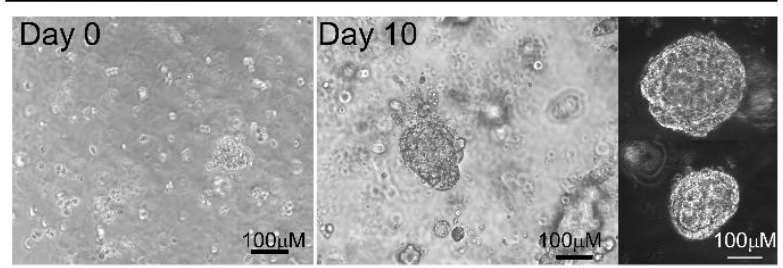

hiTSC\#11
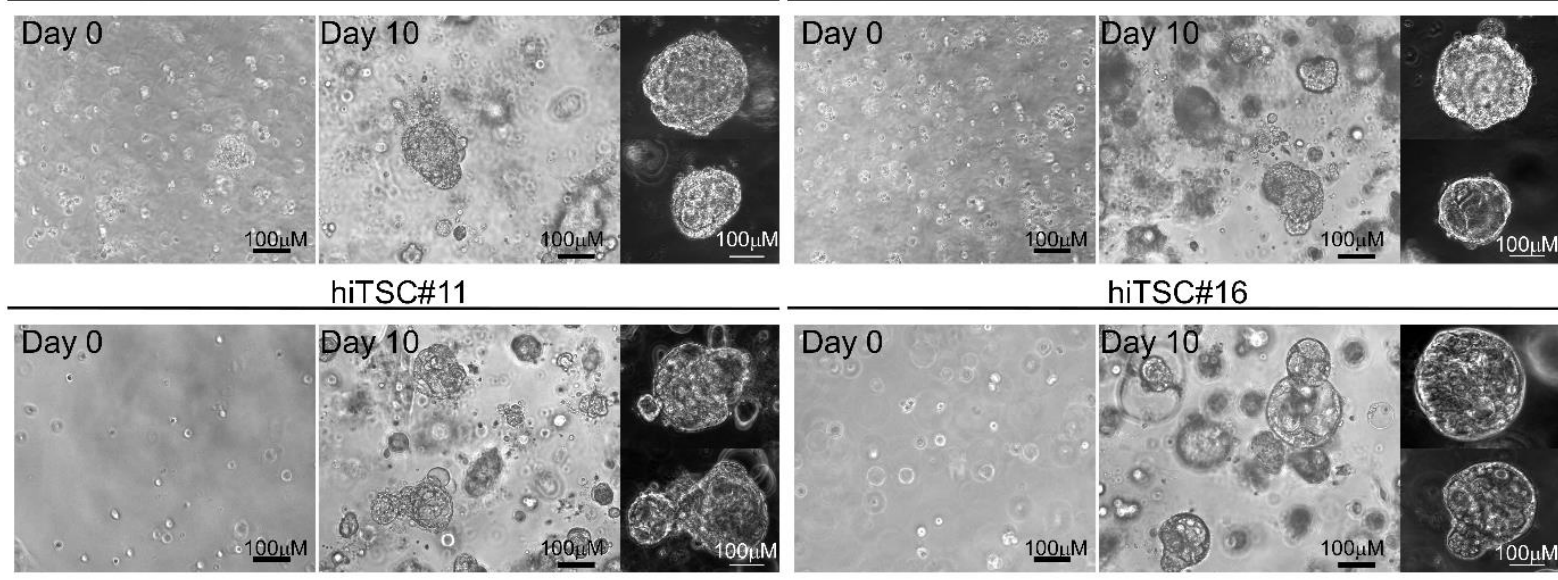

hiTSC\#16

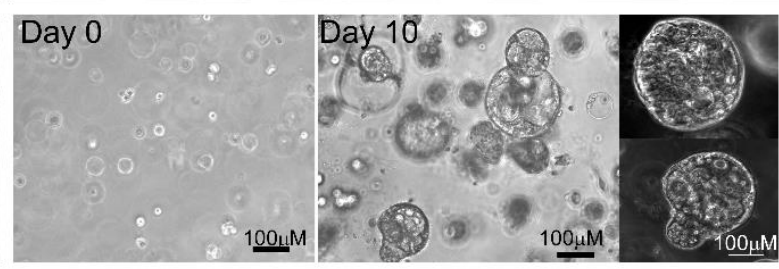

$\mathbf{E}$

hbdTSC\#2 organoids

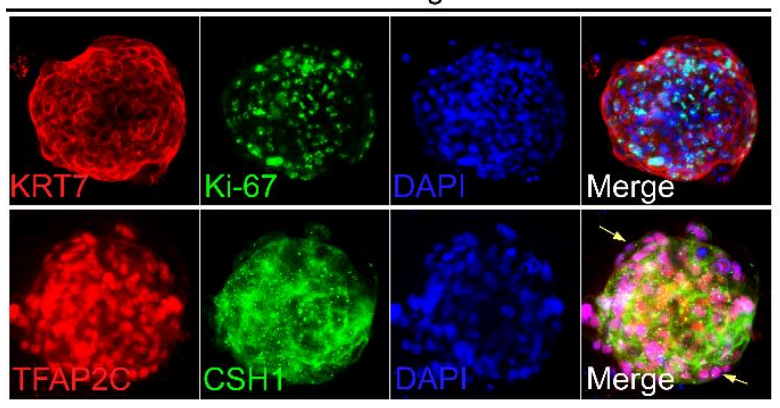

hiTSC\#11 organoids
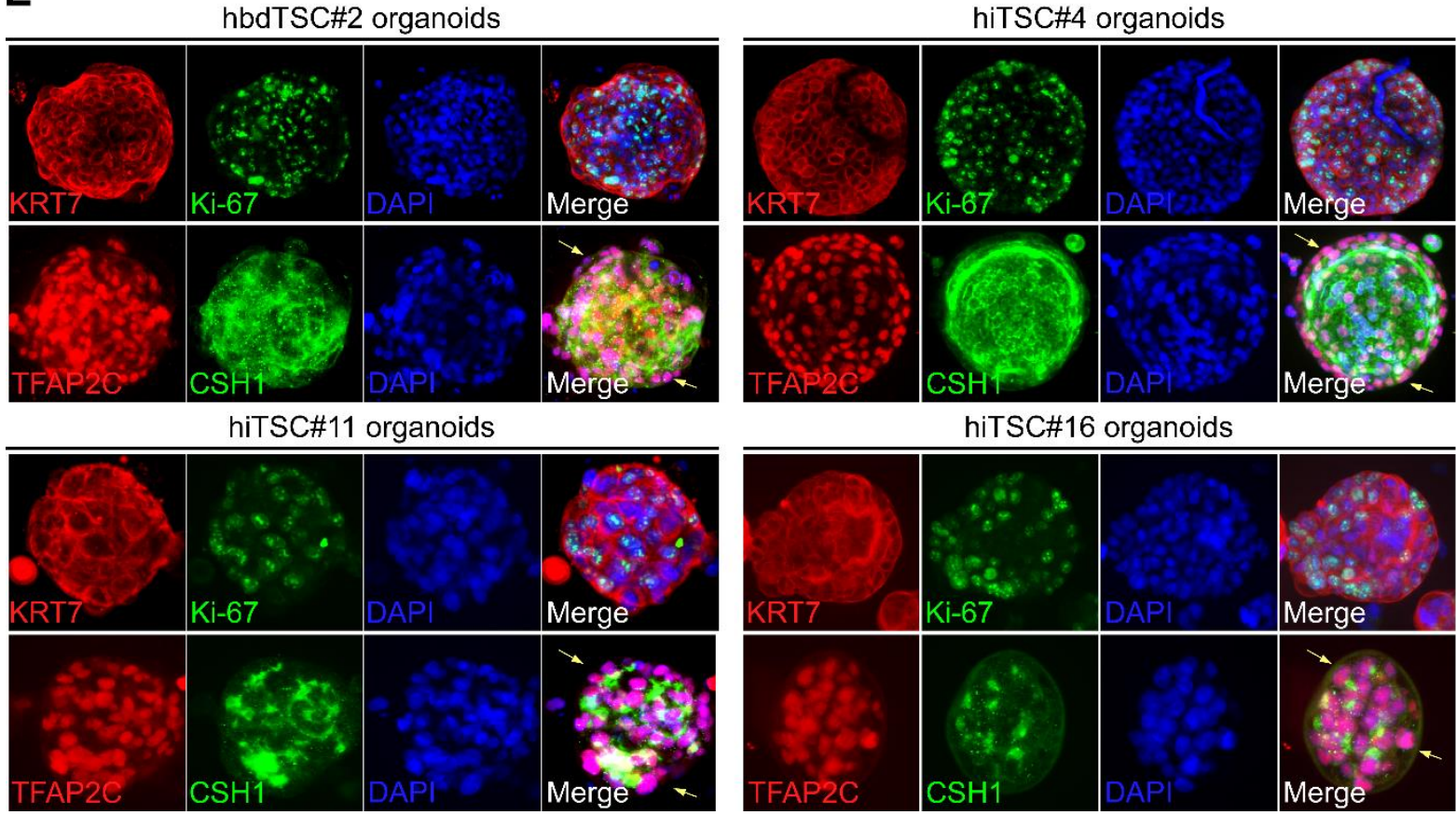

hiTSC\#16 organoids

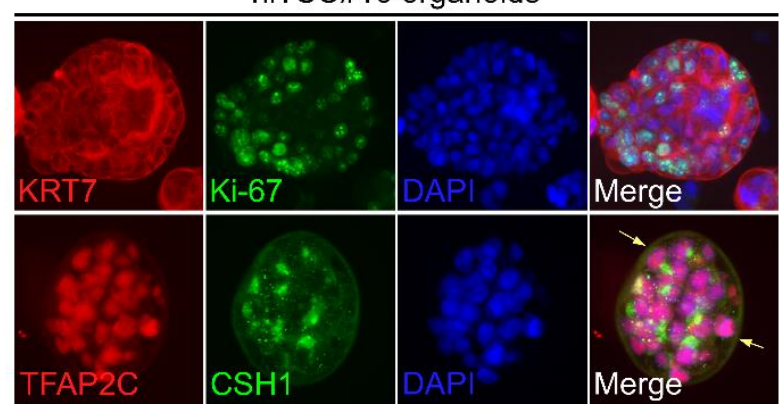


Figure 6. hiTSCs form trophoblastic lesions in NOD/SCID mice and functional organoids in matrigel.

(A) Image of the lesions that were extracted from NOD/SCID mice following $\sim 9$ days of subcutaneous 


\section{Figure 7}

A

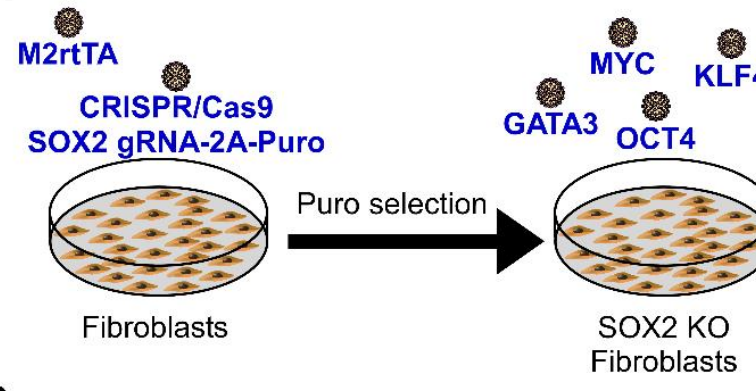

B

SOX2 locus
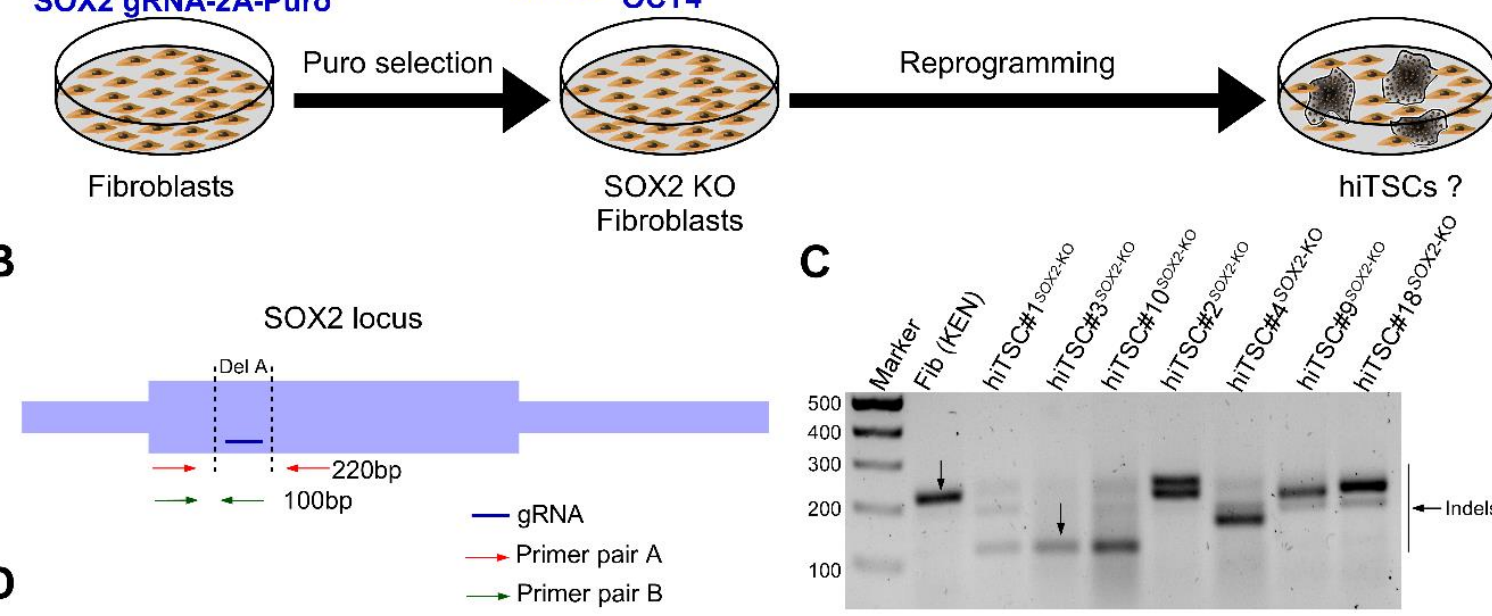

hiTSCs?

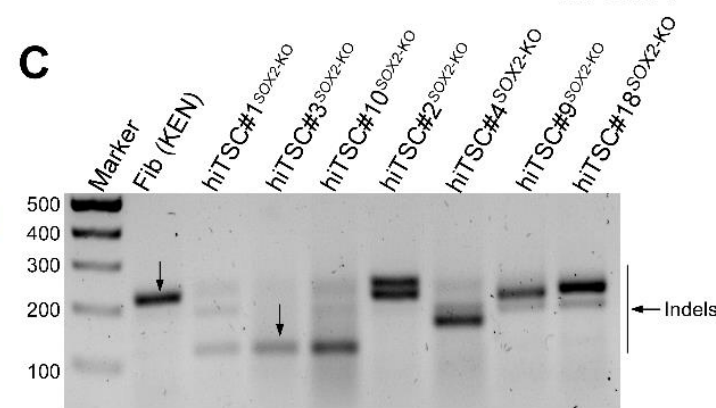

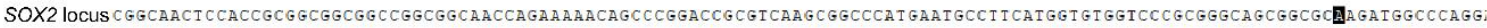

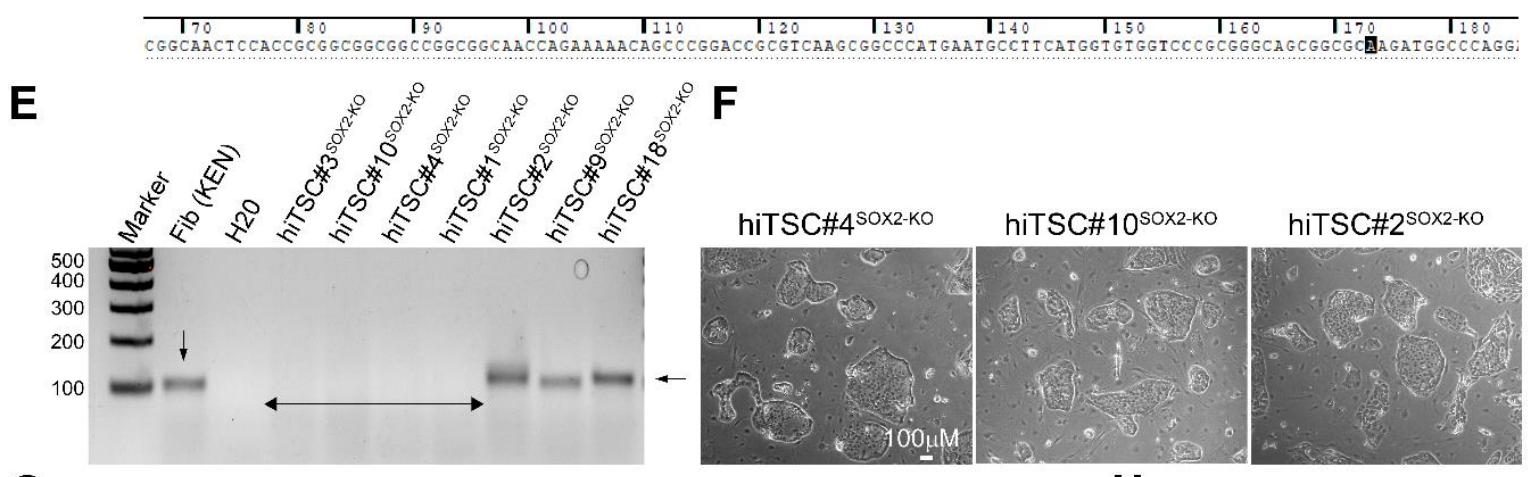

G

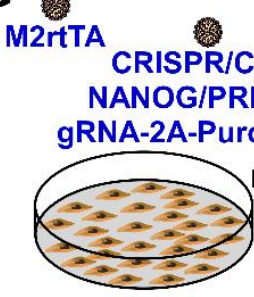

Fibroblasts

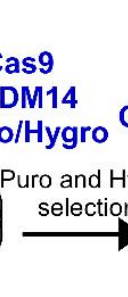

Hygro
selection
sand Hygro
NANOG/PRDM14

DKO Fibroblasts
H

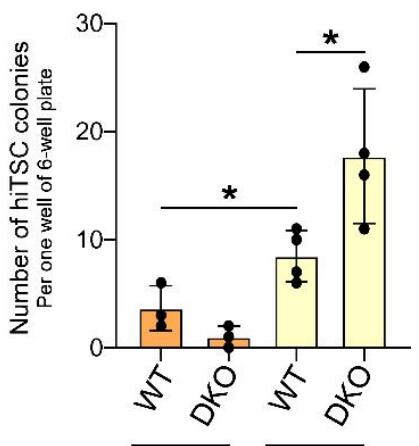

I

DKO hiTSCs

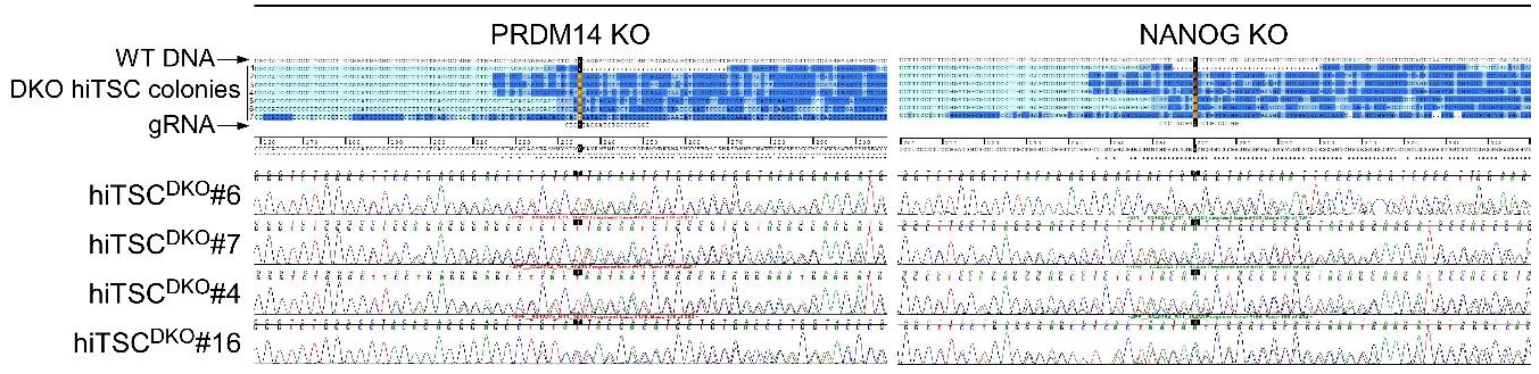


bioRxiv preprint doi: https://doi.org/10.1101/2021.11.10.468044; this version posted November 11, 2021. The copyright holder for this

preprint (which was not certified by peer review) is the author/funder, who has granted bioRxiv a license to display the preprint in perpetuity. It is made available under aCC-BY-NC-ND 4.0 International license.

SUPPLEMENTARY DATA

Figure S1
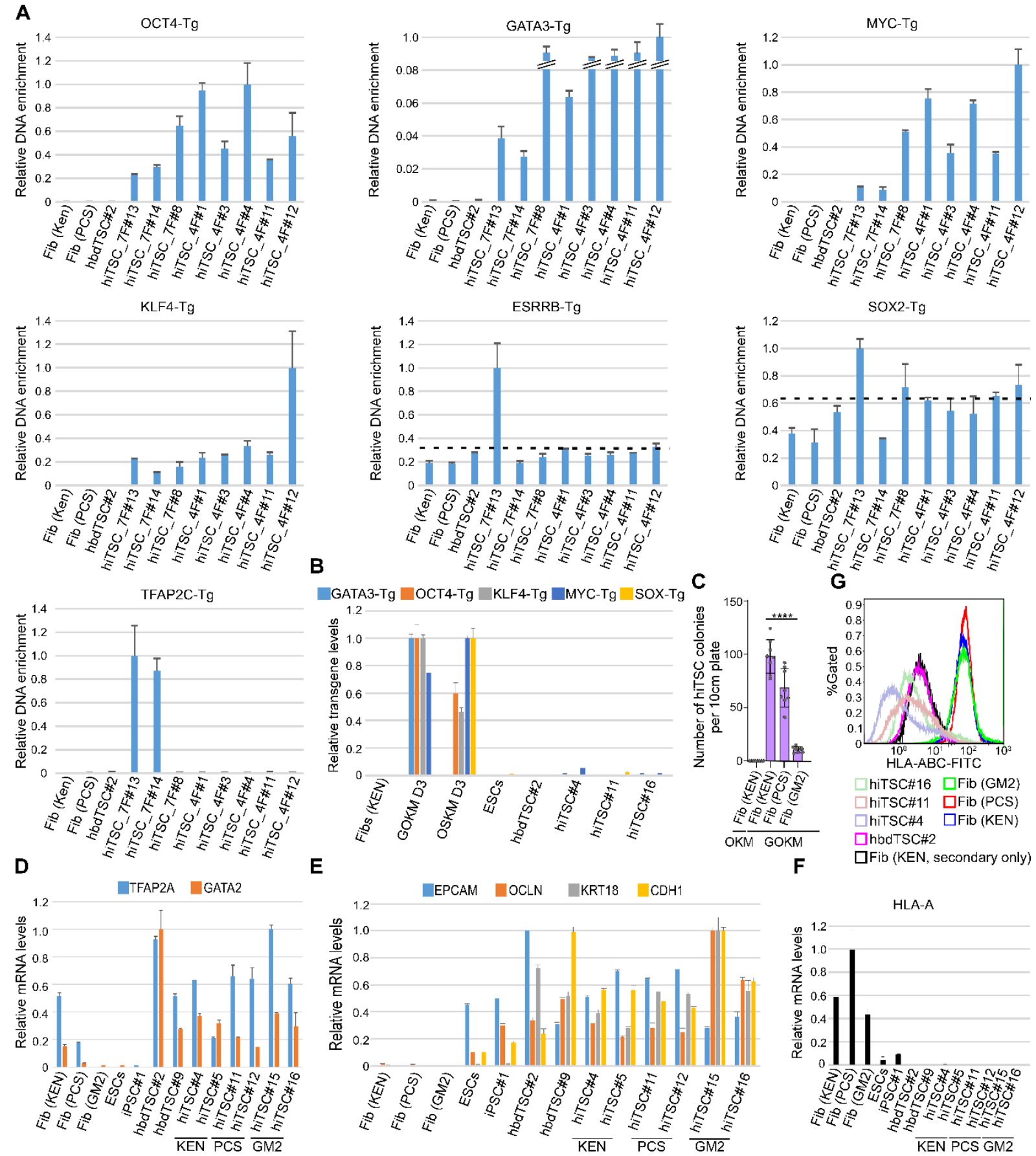
Figure S1. Fibroblasts reprogrammed to hiTSCs with forced expression of GOKM undergo MET and

express hTSC markers. (A) GATA3, OCT4, KLF4 and MYC transgens are present in all hiTSC colonies.

qPCR analysis of the indicated transgenes in hiTSC colonies and negative controls HFFs (KEN), HFFs

(PSC) and hbdTSC\#2. Transgene integration was assessed by forward primers designed for the last

Table 1). The highest sample for each transgene was set to 1 . Results were normalized to an intronic GOKM or OSKM infected fibroblasts following 3 days of dox exposure. Uninfected fibroblasts and hbdTSCs were used as negative controls for transgene expression. The highest sample for each transgene was set to 1 . Results were normalized to the mRNA levels of the housekeeping control gene GAPDH and are shown as fold change. Error bars indicate standard deviation between two duplicates. hiTSC colonies were derived from 3 independent reprogramming experiments. (C) hiTSC reprogramming efficiency varies between different primary fibroblast lines. Graph showing an average number of hiTSC colonies generated by either OKM or GOKM in the indicated fibroblast lines. Error bars indicate standard deviation between 8 replicates. ${ }^{* * *}$-value $<0.001$ as calculated by GraphPad 
Figure S2

A

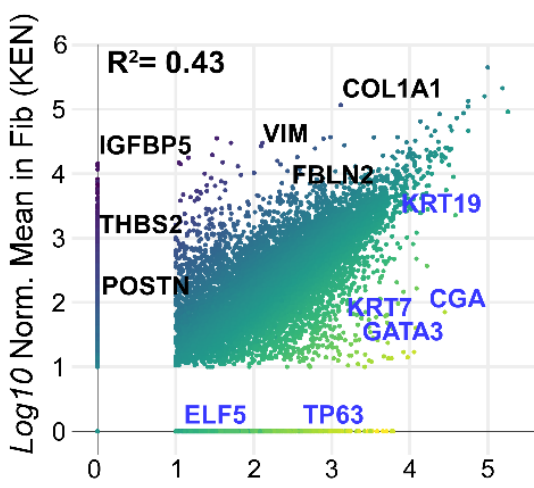

Log10 Norm. Mean in hbdTSC\#2

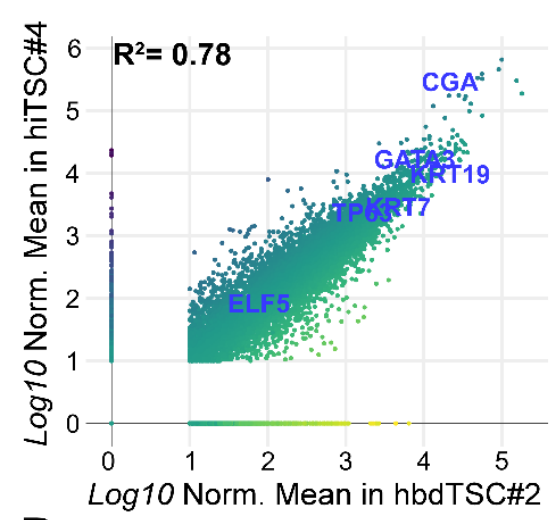

B

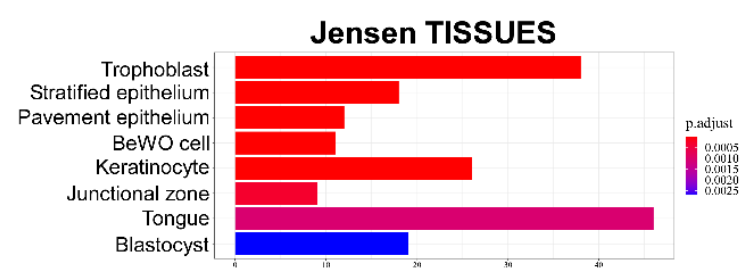

D

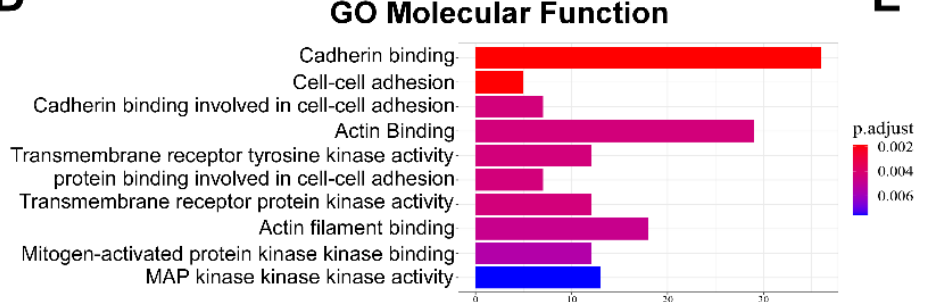

C

E
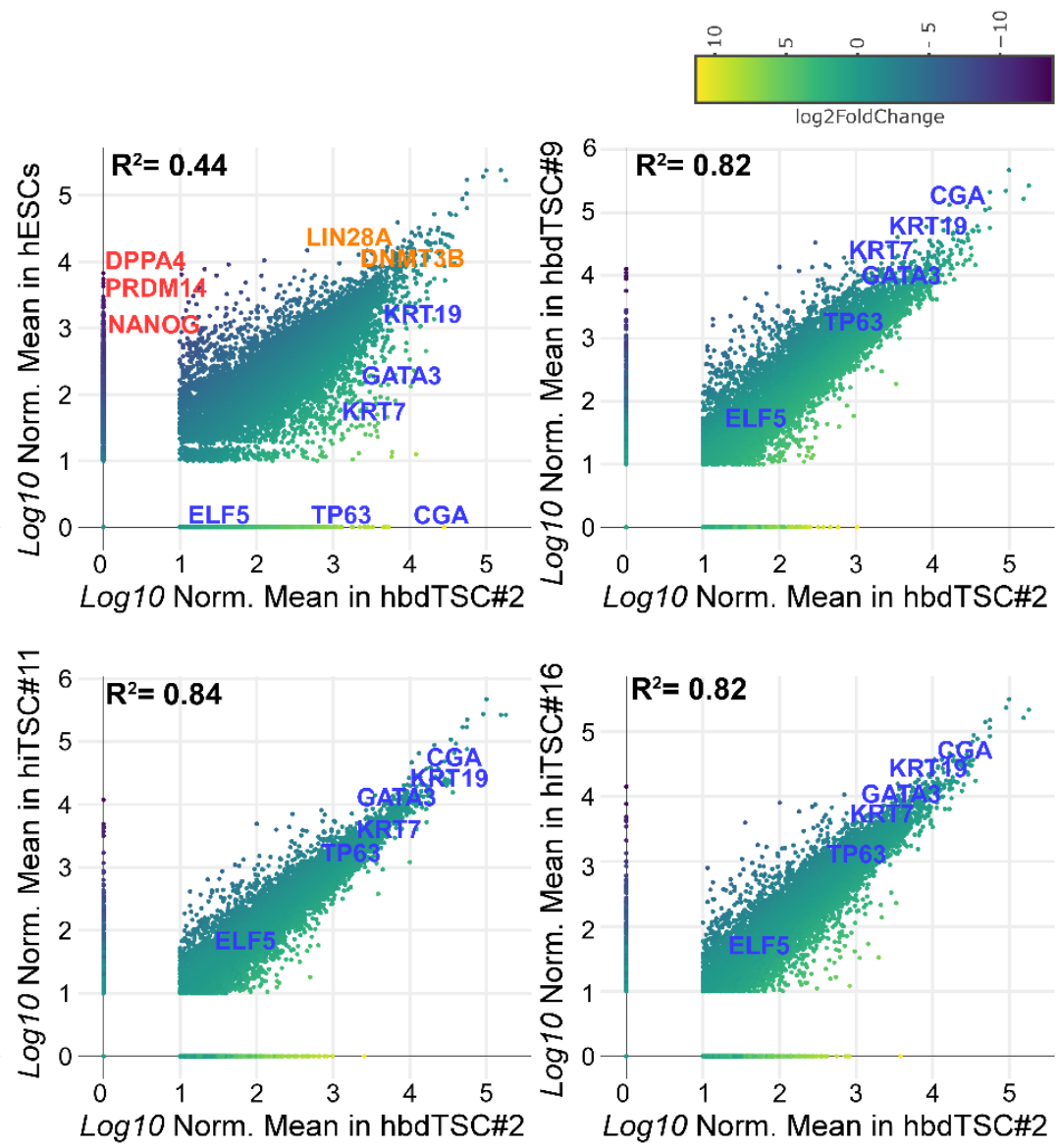

ENCODE and ChEA Consensus TFs

$$
\begin{array}{r|}
\text { TP63 } \\
\text { SUZ12. } \\
\text { NANOG } \\
\text { GATA1 } \\
\text { GATA2 } \\
\text { ZEB1 } \\
\text { TCF3 } \\
\text { EZH2 } \\
\text { SMAD4. } \\
\text { KLF4. }
\end{array}
$$

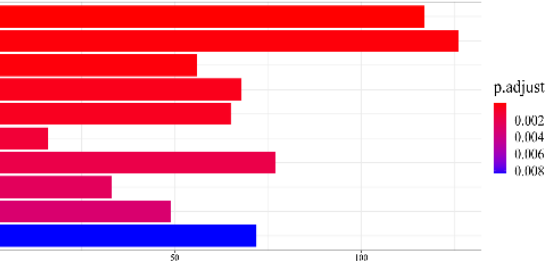

MsigBD Hallmark

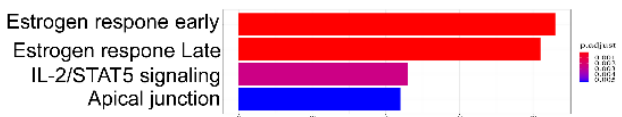


Figure S2. RNA-seq analysis indicates that hiTSCs have a transcriptome enriched for gene ontology

terms related to placental development. (A) Scatter plots displaying pairwise correlations of gene expression levels for hbdTSC\#2 vs KEN fibroblasts, hbdTSC\#2 vs hESCs, hbdTSC\#2 vs hbdTSC\#9, hbdTSC\#2 vs hiTSC\#4, hbdTSC\#2 vs hiTSC\#11, and hbdTSC\#2 vs hiTSC\#16. Two RNA-seq replicates 
bioRxiv preprint doi: https://doi.org/10.1101/2021.11.10.468044; this version posted November 11, 2021. The copyright holder for this

preprint (which was not certified by peer review) is the author/funder, who has granted bioRxiv a license to display the preprint in perpetuity. It is made available under aCC-BY-NC-ND 4.0 International license.

Figure S3

A

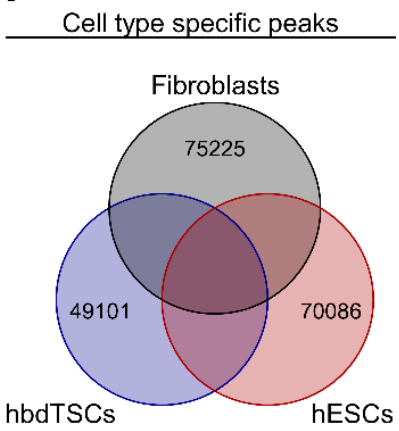

D

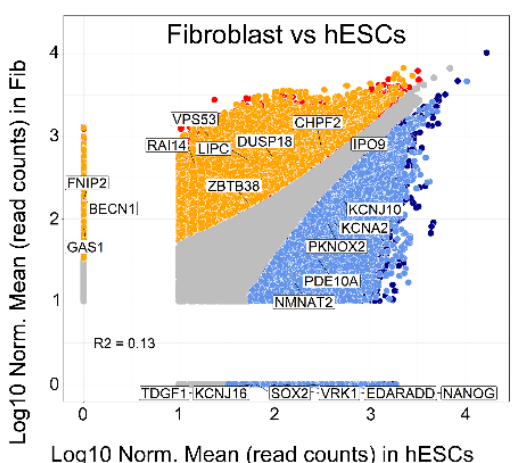

B

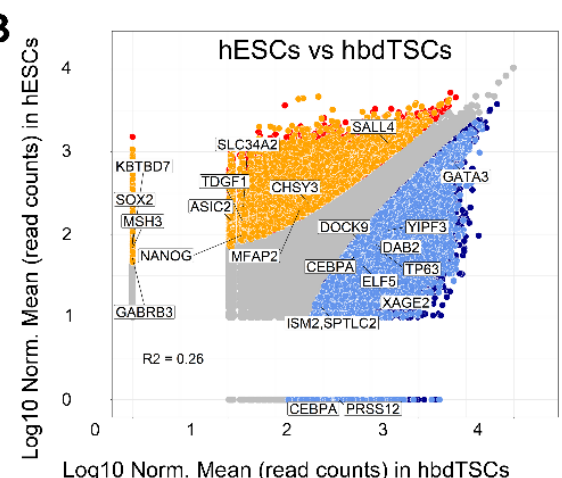

$\mathbf{E}$

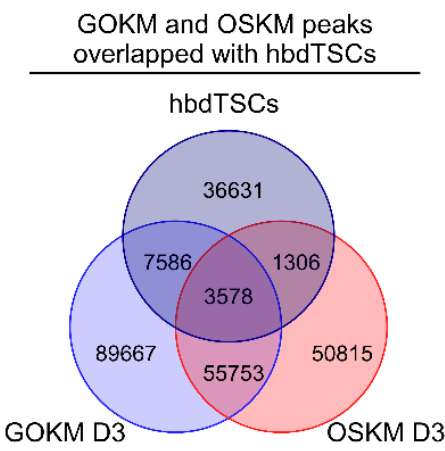

C

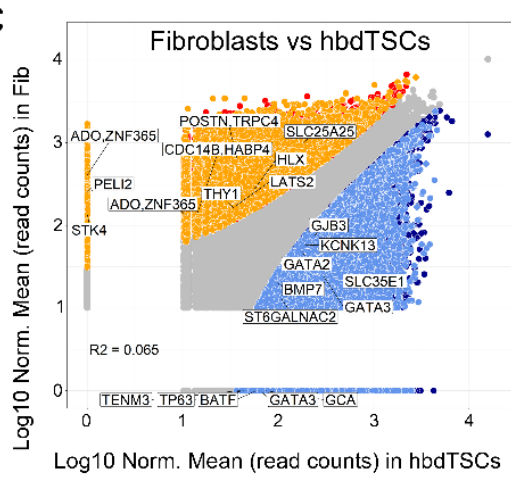

$\mathbf{F}$

GOKM and OSKM peaks overlapped with hESCs

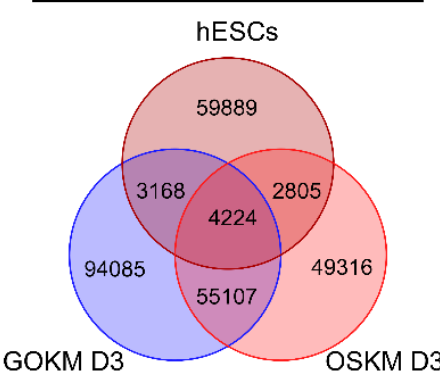

Different hESC-specific genes with different peaks for GOKM D3 and OSKM D3

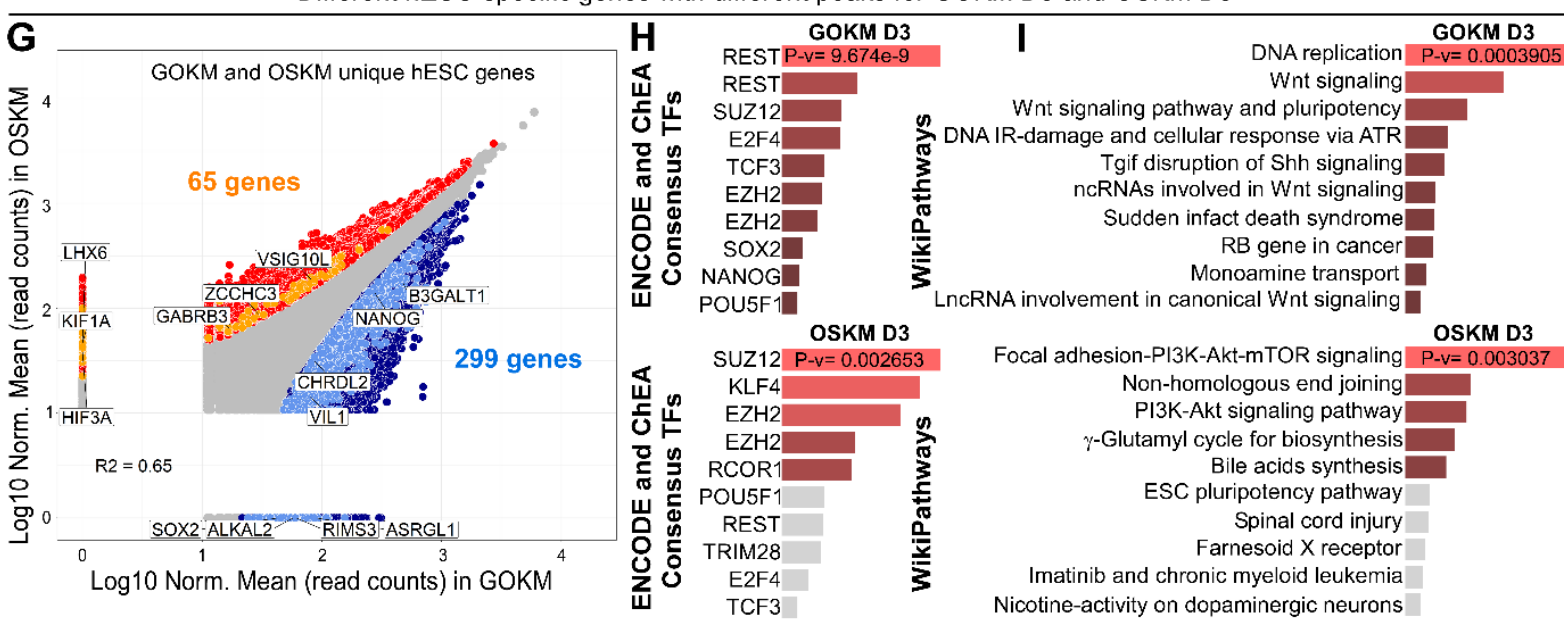

J

K

$\mathbf{L}$

GOKM D3 vs OSKM D3 peaks (101,562 peaks) hESC-specific peaks $(16,703)$
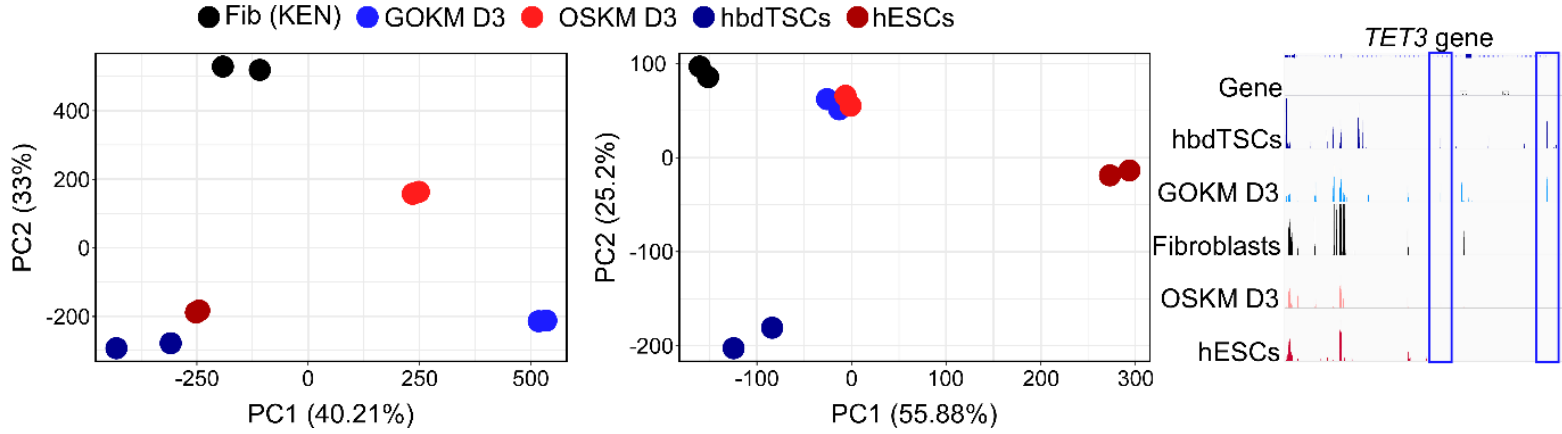
Figure S3. ATAC-seq analysis on GOKM and OSKM-transduced cells following 3 days of transgene

induction. (A) Venn diagram of ATAC-seq showing peaks that are specific to fibroblasts, hbdTSCs, and

hESCs (FDR< 0.01). (B-D) Scatter plots displaying pairwise correlations and differentially accessible differentially accessible peaks between GOKM D3, OSKM D3 with FDR $<0.05$. Peaks that are specific to GOKM D3 or OSKM D3 are labeled by dark blue and red, respectively. Peaks associated with genes specific to the GOKM reprogramming and are specific to the hESC state were labeled with light blue, while peaks associated with genes specific to the OSKM reprogramming and are specific to the hESC state are labeled with orange. 299 genes are found to overlap between hESC-specific genes and peaks that are associated to these genes specifically in GOKM D3, while 65 genes are found to overlap between hESC-specific genes and peaks that are associated with these genes in OSKM D3. (H-I) GO terms for 299 and 65 genes in (G) under the categories "ENCODE and ChEA Consensus TFs" and that are differential between OSKM D3 and GOKM D3. A significant change in chromatin accessibility 
bioRxiv preprint doi: https://doi.org/10.1101/2021.11.10.468044; this version posted November 11, 2021. The copyright holder for this

preprint (which was not certified by peer review) is the author/funder, who has granted bioRxiv a license to display the preprint in perpetuity. It is made available under aCC-BY-NC-ND 4.0 International license.

Figure S4

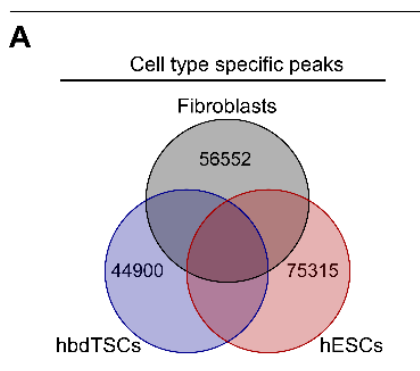

$$
\text { D }
$$

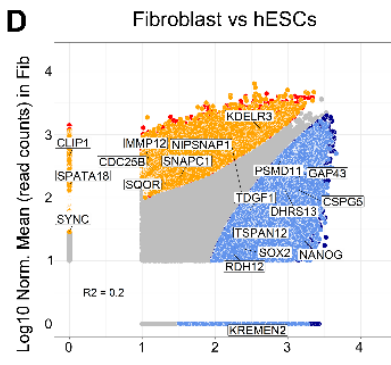

Log10 Norm. Mean (read counts) in hESCs
ChIP-seq $(288,653$ peaks $)$

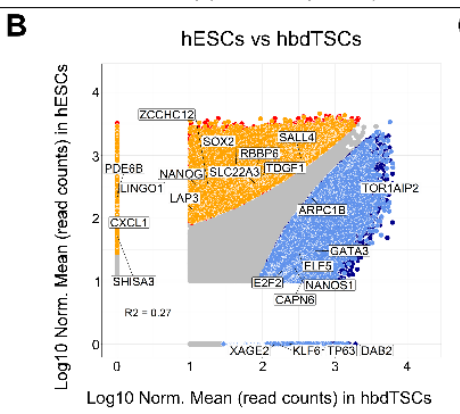

E

$\mathbf{F}$
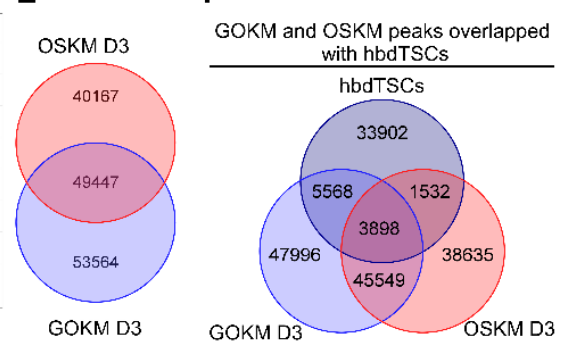

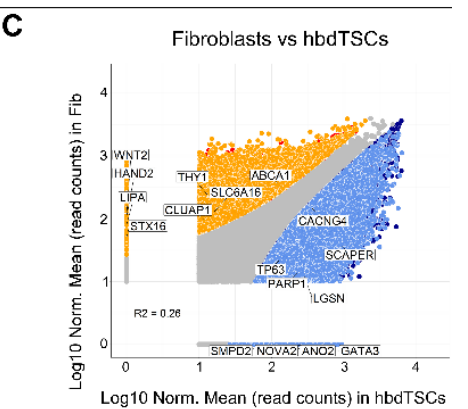

G
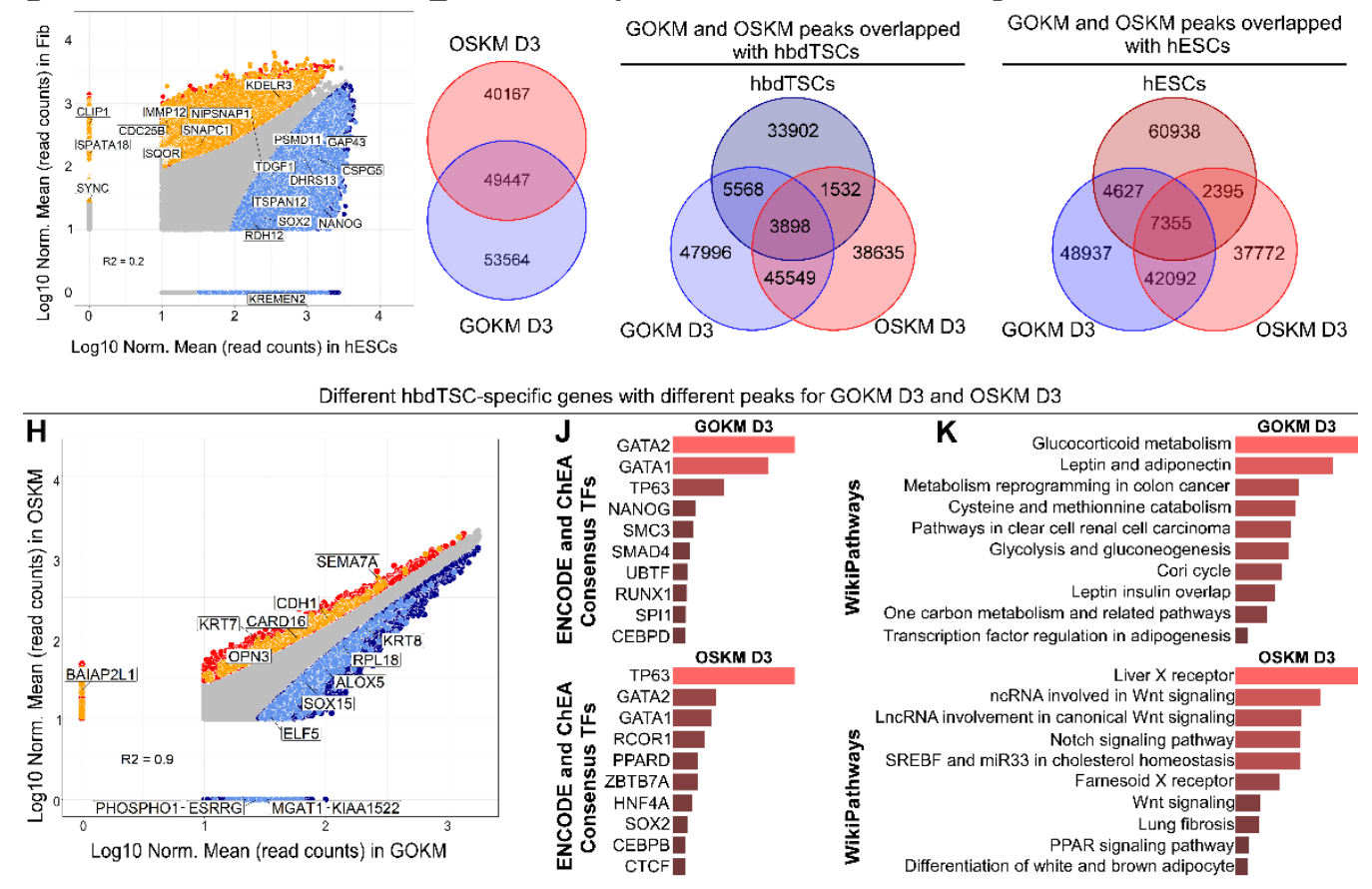

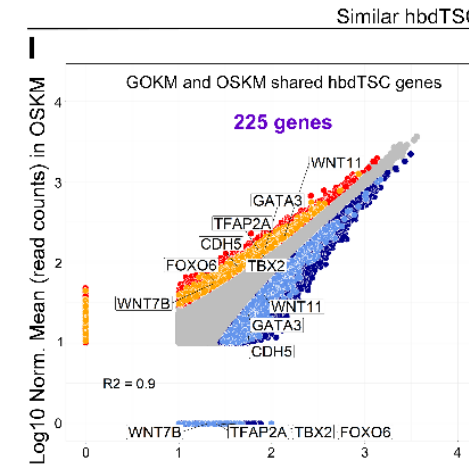

Log10 Norm. Mean (read counts) in GOKM

P $\bullet$ Fib (KEN) •GOKM D3 $\bullet$ OSKM D3

$$
\bullet \text { hbdTSCs } \bullet \text { hESCs }
$$

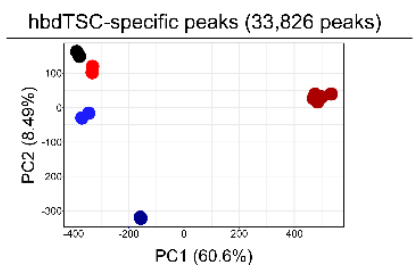

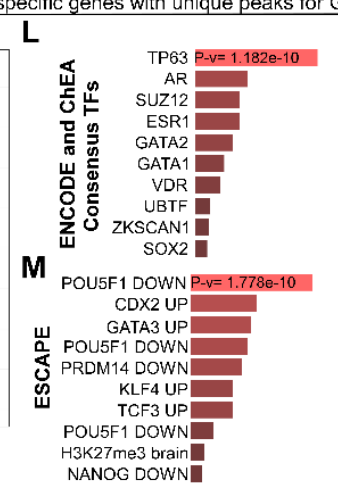

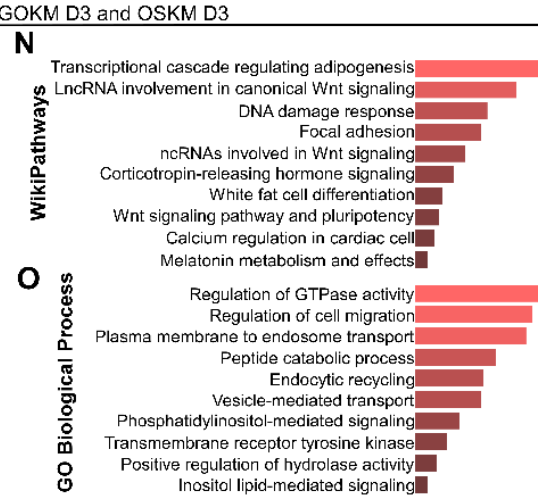



deposition peaks between GOKM D3 and OSKM D3 with FDR< 0.05. Peaks that are specific to GOKM 
bioRxiv preprint doi: https://doi.org/10.1101/2021.11.10.468044 this version posted November 11 2021. The copyright holder for this preprint (which was not certified by peer review) is the author/funder, who has granted bioRxiv a license to display the preprint in perpetuity. It is made available under aCC-BY-NC-ND 4.0 International license.

\section{Figure S5}

A hbdTSC\#2

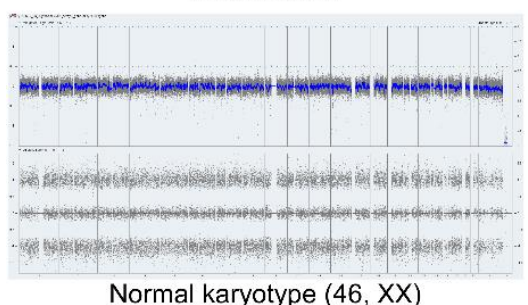

hbdTSC\#9

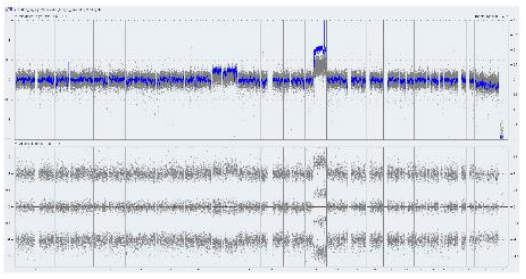

Karyotype (46, XX)

$-30 \%$ mosaic gain of chromosome 7 Gain $(\mathrm{CN}=3)$ chromosome $11 \mathrm{q}$
hiTSC\#4

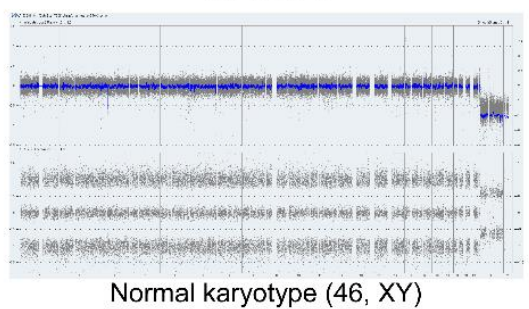

hiTSC\#2

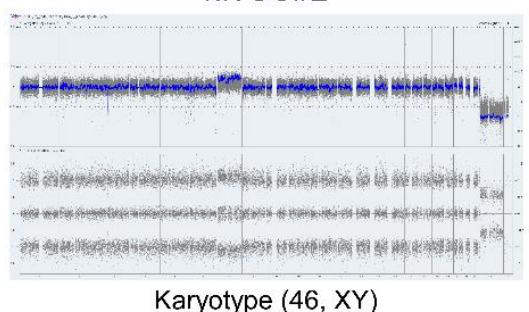

$\sim 30 \%$ mosaic gain of chromosome 7
hiTSC\#11

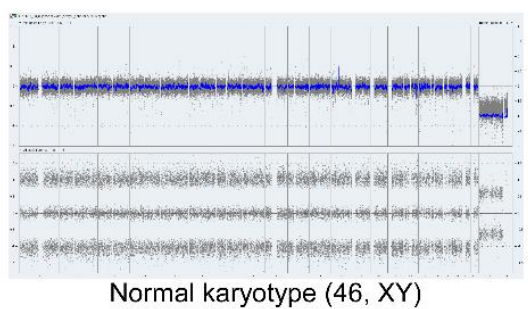

hiTSC\#1

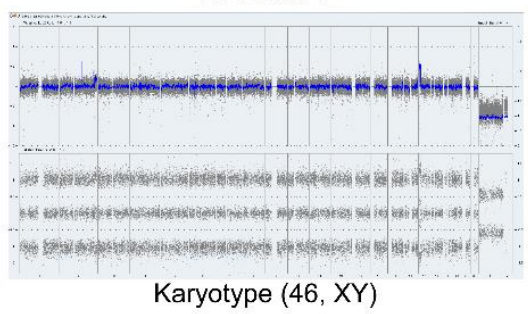

$-70 \%$ mosaic gain of the terminal end (19MB) of chromosome $2 q$

$70 \%$ mosaic gain of the terminal end (13MB) of chromosome 17p
B

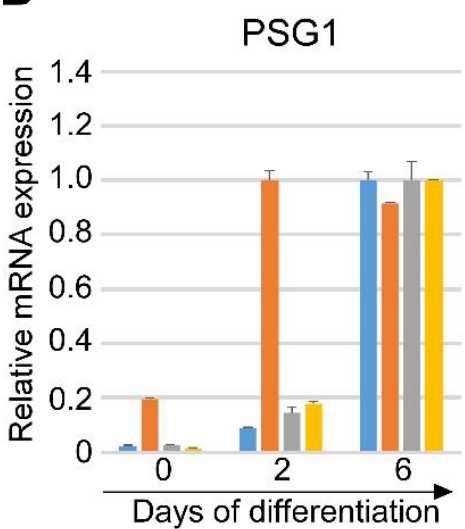

CHSY1

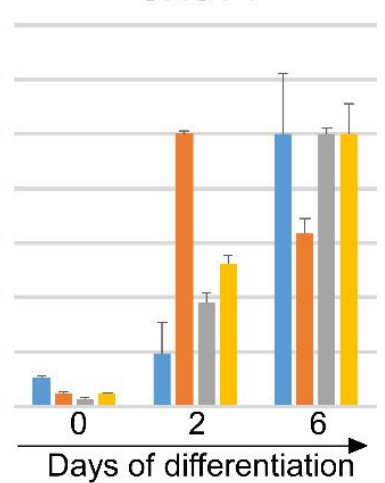

C

hiTSC\#16
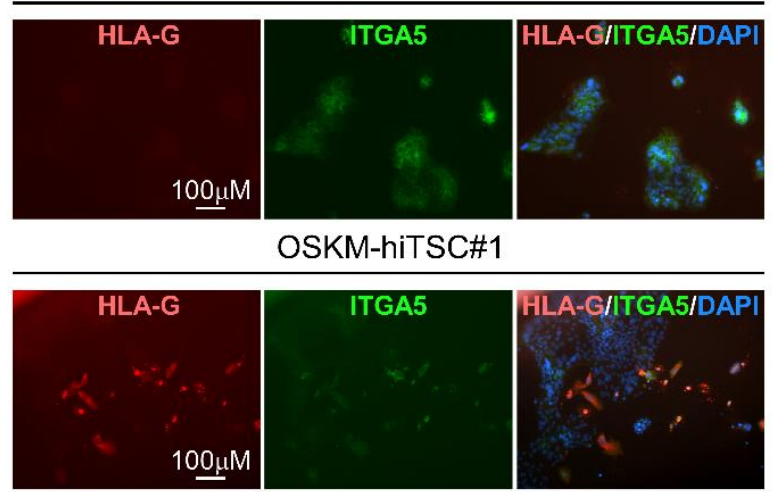

D

Non-integrating episomal vectors pCXLE-hGATA3, pCXLE-hOCT4-shp53, pCXLE-hKLF4, pCXLE-hUTF1-MYC, pCXWB-EBNA1

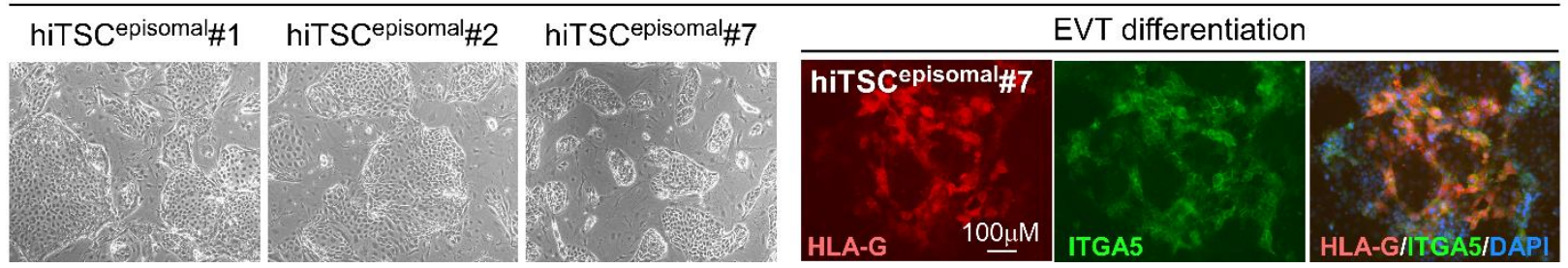


Figure S5. hiTSCs can maintain normal karyotype and differentiate into ST and EVT-like cells. Both two lines reveals that hbdTSC\#2 is heterozygous for RB mutation and hbdTSC\#9 is heterozygous for RB and Marfan mutations (A) Plots displaying the karyotype of hbdTSC and hiTSC lines. Two hbdTSC lines, hbdTSC\#2 and hbdTSC\#9, and four hiTSC clones, hiTSC\#1, hiTSC\#2, hiTSC\#4 and hiTSC\#11, were PSG1 and CHSY1 at days 0, 2 and 6 in ST differentiation protocol. The highest sample for each gene in each colony was set to 1 . Results were normalized to the mRNA levels of the housekeeping control gene GAPDH and are shown as fold change. Error bars indicate standard deviation between two duplicates. (C) Immunofluorescent staining for the EVT-specific markers HLA-G and ITGA5 and DAPI nuclear staining in PFA-fixated hiTSC\#16 and OSKM-hiTSC\#1 following 14 days of EVT differentiation. 
bioRxiv preprint doi: https://doi.org/10.1101/2021.11.10.468044; this version posted November 11, 2021. The copyright holder for this preprint (which was not certified by peer review) is the author/funder, who has granted bioRxiv a license to display the preprint in perpetuity. It is made available under aCC-BY-NC-ND 4.0 International license.

\section{Figure S6}

A
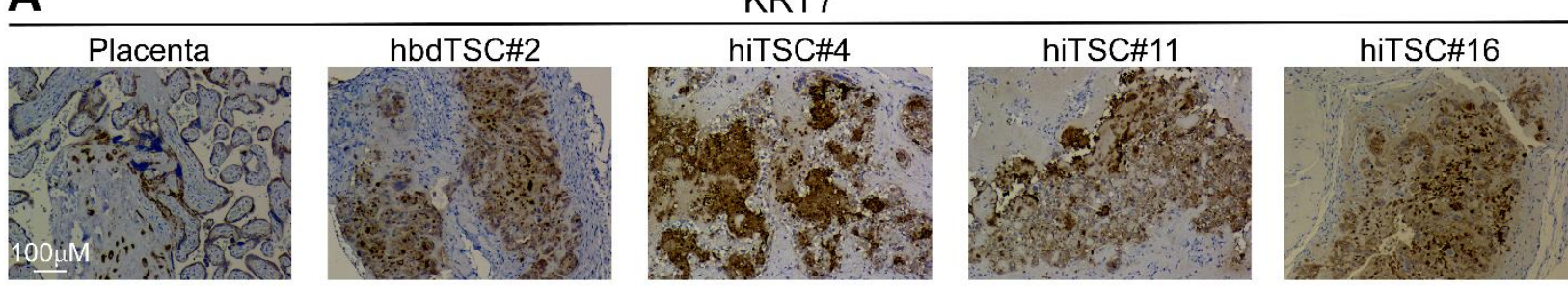

HLA-G
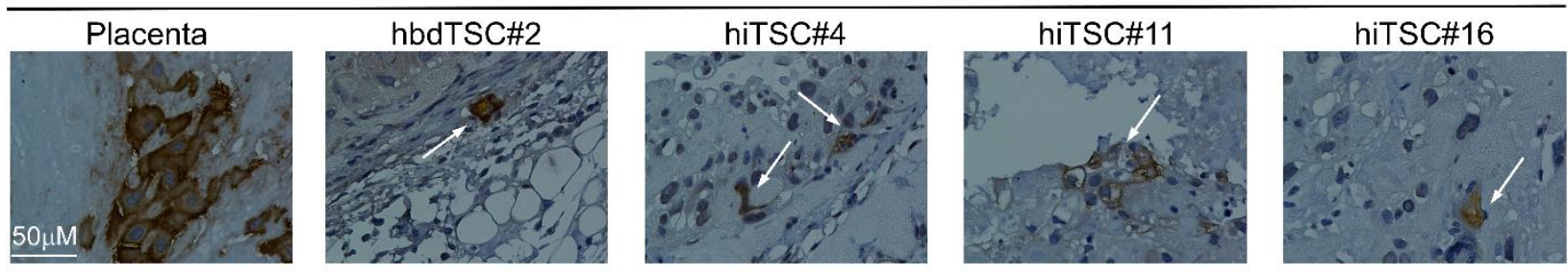

\section{$\mathrm{CSH} 1$}
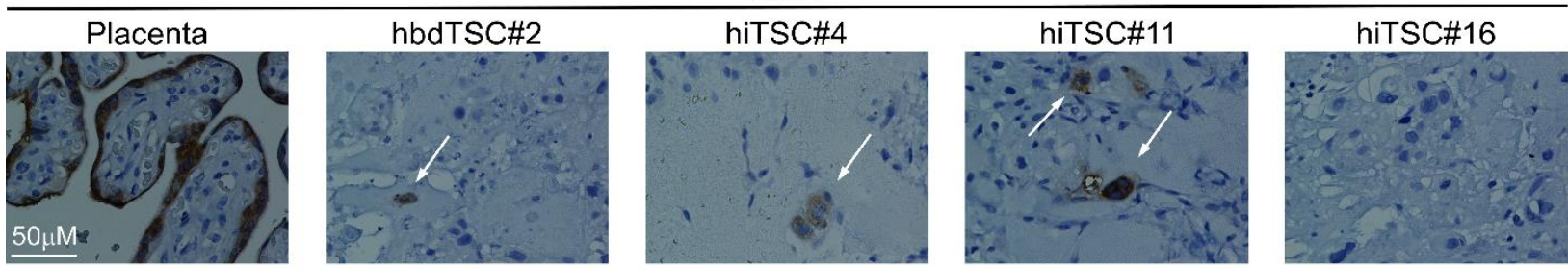

B hbdTsCs

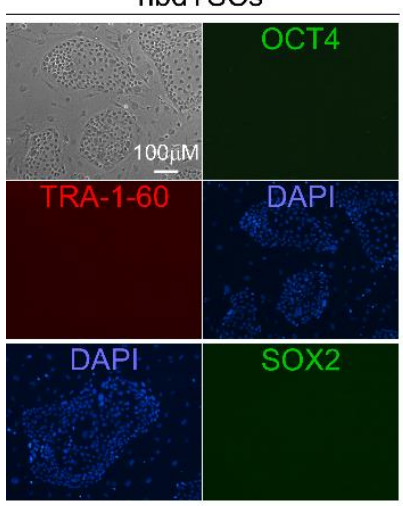

hESCs

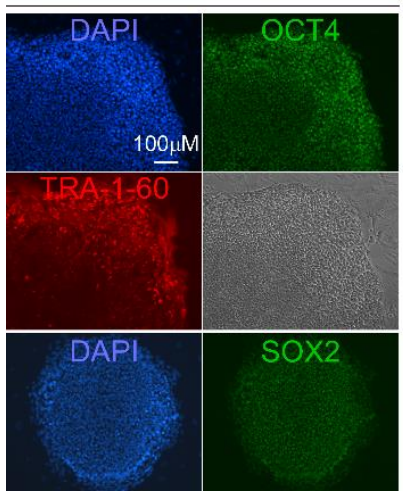

hiTSC\#4

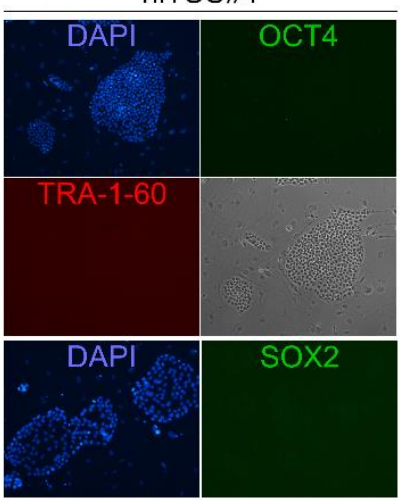

OKM-IPSC\#1

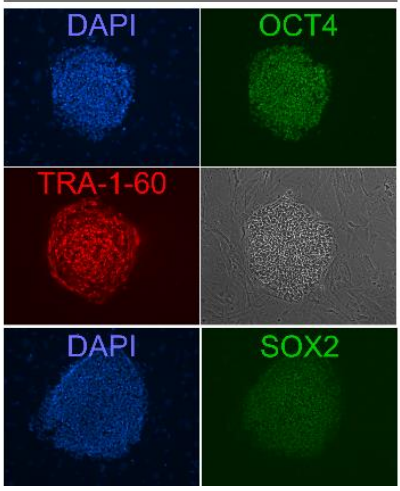

hiTSC\#11

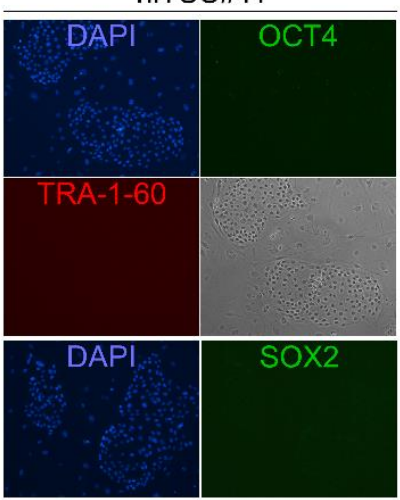

GOKM-iPSC\#1

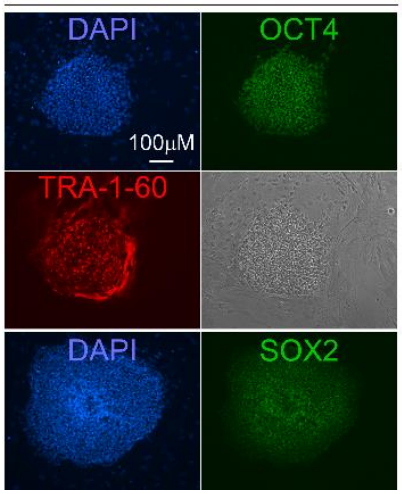

hiTSC\#16

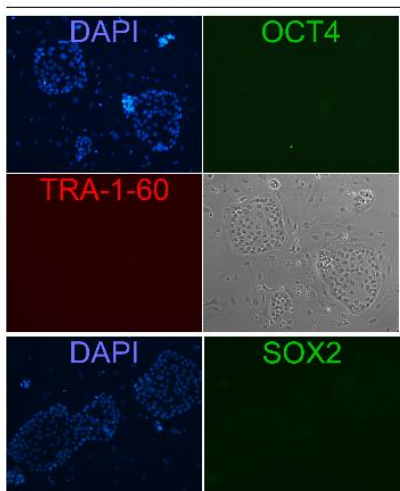

GOKM-iPSC\#2

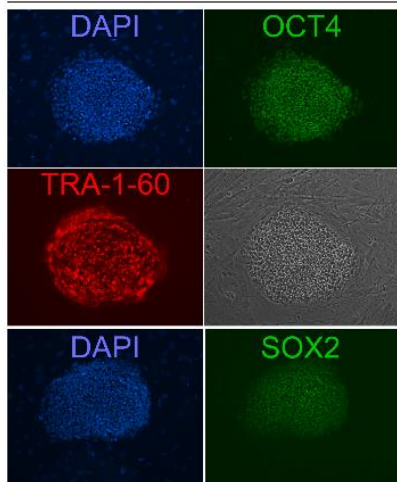


Figure S7

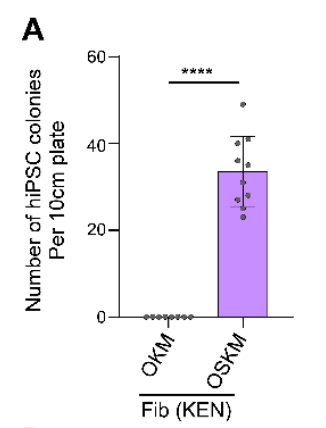

B

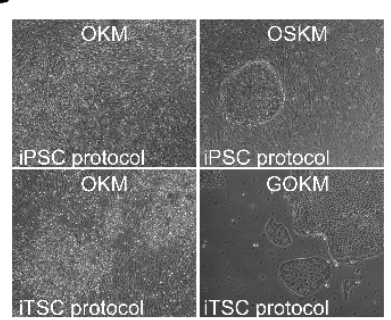

Endogenous GATA3

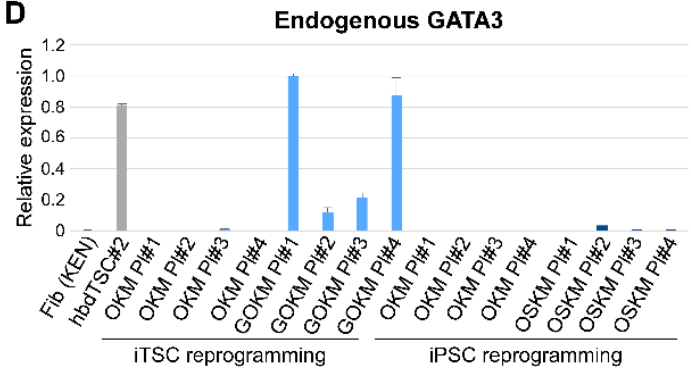

F

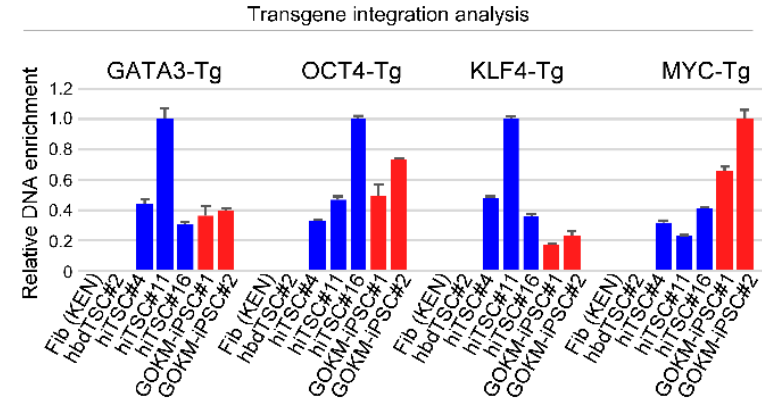

H
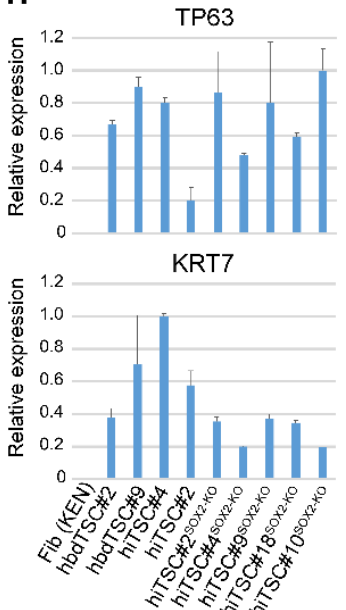

$\mathbf{J}$
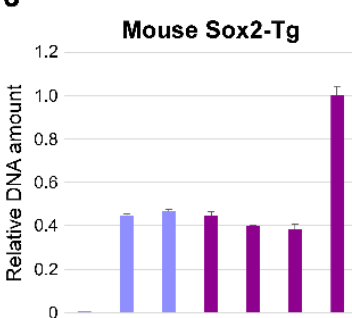

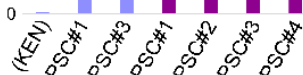

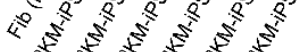

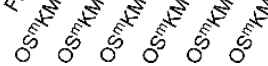

GATA3 ${ }^{\text {endo }}$

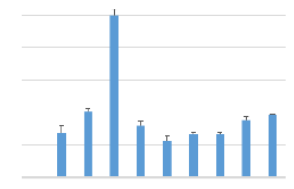

TFAP2C

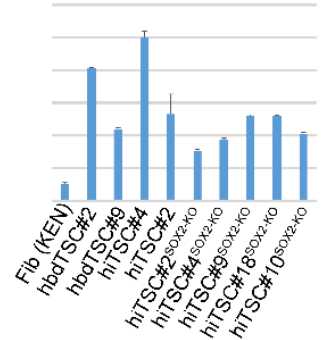

K

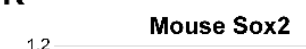

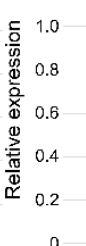

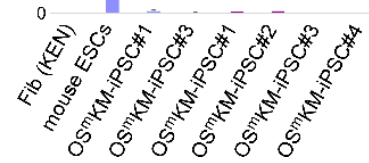

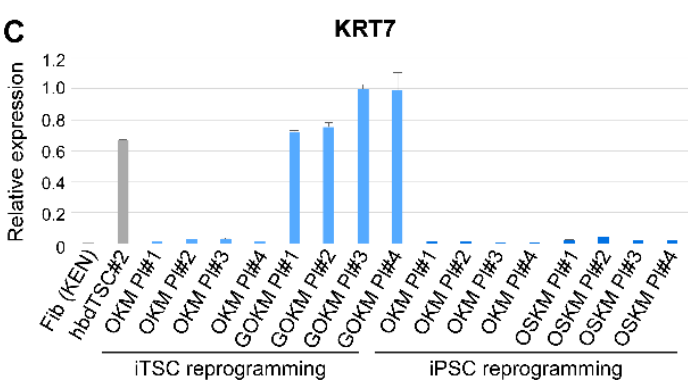

E

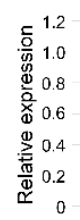

Endogenous OCT4

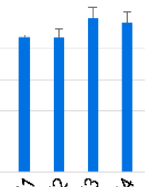

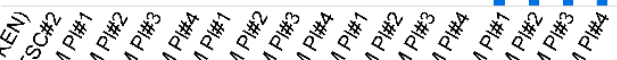

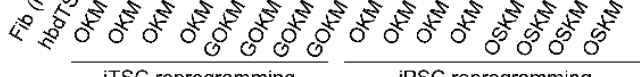

G $\square$ TRA-1-60 sorted cells (FITC) \# of hiPSC colonies emerged

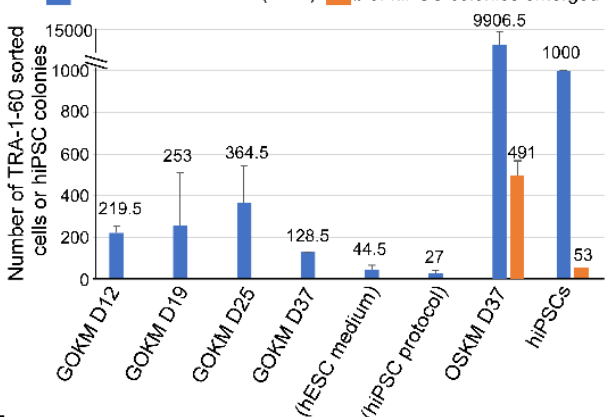

I

WT Fib

gRNA SOX2 Fib

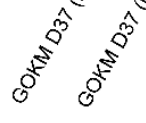

sox2 locus

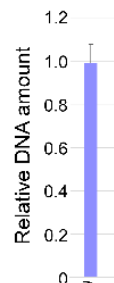

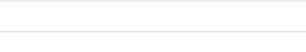


Figure S7. OKM are incapable of generating hiTSCs and GOKM do not acquire pluripotency during

hiTSC formation. Fibroblasts were transduced with OKM, GOKM or OSKM and reprogramming efficiency in generating iPSCs or hiTSCs was examined (A) Graph showing an average number of hiPSC colonies generated by either OKM or OSKM. Error bars indicate standard deviation between 8-10 replicates. ${ }^{* * * *}$-value $<0.001$ as calculated by GraphPad Prism using Student's t-test. Graph depicting the average number of hiTSC colonies generated by OKM and GOKM is located in Figure S1C. Note, following multiple attempts we were able to derive two OKM and two GOKM-hiPSC colonies (See Figure S6B). (B, top) Bright field images of representative areas in plates which were reprogrammed with OKM or OSKM using hiPSC reprogramming protocol (left) and following colony isolation (right). with OKM, GOKM or OSKM following hiPSC or hiTSC reprogramming protocols as specified in the graphs. The highest sample for each gene was set to 1 . Results were normalized to the mRNA levels of the housekeeping control gene GAPDH and are shown as fold change. Error bars indicate standard deviation between two duplicates. (F) GPCR analysis for the relative DNA enrichment of GOKM transgene integration in the indicated samples. Note, the two GOKM-iPSC colonies contain low levels of KLF4-Tg and high levels of MYC-Tg compared to GOKM-hiTSC colonies. Transgene integration was assessed using forward primers designed for the last exon of the transgene with reverse primers matching the sequence of the FUW-TetO plasmid (See Table 1). The highest sample for each transgene was set to 1. Results were normalized to unaffected genomic region of the GAPDH gene and are shown analysis of mRNA levels of TSC-specific markers TP63, GATA3 ${ }^{\text {endo }}$, KRT7 and TFAP2C in Fibroblast (KEN), two hbdTSC clones, two hiTSC clones and five SOX2 KO hiTSC clones. The highest sample for each gene was set to 1 . Results were normalized to the mRNA levels of the housekeeping control gene GAPDH and are shown as fold change. Error bars indicate standard deviation between two duplicates. (I) qPCR 
constitutively active Cas9 together with a gRNA against the SOX2 coding region (dark purple). WT

fibroblast (KEN) and fibroblasts transduced with lentiviral vector encoding for puromycin resistance

and constitutively active Cas9, but without gRNA, were used as negative controls. Note that while 4

out of 6 GOKM-derived hiTSC clones displayed homozygous deletions for the human SOX2 genomic

locus, all the examined $\mathrm{OS}^{\mathrm{m}} \mathrm{KM}$-derived hiPSC clones exhibited at least one intact SOX2 allele (using

primer pair B, see Figure 7 and Table 1). The highest sample for each gene was set to 1 . Results were

all six OSKM-derived hiPSC clones display mouse Sox2 transgene integration in their genome without

leaky expression and high levels of endogenous human SOX2 gene expression. The highest sample for

each gene was set to 1 . Results were normalized to unaffected genomic region of the GAPDH gene 


\begin{tabular}{|c|c|c|}
\hline Gene & Application & Primer Sequence (5' --> 3') \\
\hline GAPDH (intronic) & $\begin{array}{l}\text { qPCR analysis of integration into } \\
\text { genomic DNA normalization }\end{array}$ & $\begin{array}{l}\text { F: TGGTATCGTGGAAGGACTCA } \\
\text { R: TTCAGCTCAGGGATGACCTT }\end{array}$ \\
\hline GATA3 (F) & $\begin{array}{l}\text { qPCR analysis of integration into } \\
\text { genomic DNA }\end{array}$ & AGCCTGTCCTTTGGACCAC \\
\hline TFAP2C (F) & $\begin{array}{l}\text { qPCR analysis of integration into } \\
\text { genomic DNA }\end{array}$ & AACCCTGGAGACCAGAGTCC \\
\hline ESRRB (F) & $\begin{array}{l}\text { qPCR analysis of integration into } \\
\text { genomic DNA }\end{array}$ & GAAAGCATCTCTGGCTCACC \\
\hline OCT4 (F) & $\begin{array}{l}\text { qPCR analysis of integration into } \\
\text { genomic DNA }\end{array}$ & CTGTCTCCGTCACCACTCTG \\
\hline SOX2 (F) & $\begin{array}{l}\text { qPCR analysis of integration into } \\
\text { genomic DNA }\end{array}$ & GCACACTGCСССТСТСАС \\
\hline KLF4 (F) & $\begin{array}{l}\text { qPCR analysis of integration into } \\
\text { genomic DNA }\end{array}$ & GACCACCTCGCCTTACACAT \\
\hline MYC (F) & $\begin{array}{l}\text { qPCR analysis of integration into } \\
\text { genomic DNA }\end{array}$ & AGCATACATCCTGTCCGTCC \\
\hline $\operatorname{mSOX} 2(\mathrm{~F})$ & $\begin{array}{l}\text { qPCR analysis of mouse transgene } \\
\text { integration into genomic DNA }\end{array}$ & GGAGCCCAGCGCCATACCG \\
\hline FUW plasmid (R) & $\begin{array}{l}\text { qPCR analysis of integration into } \\
\text { genomic DNA }\end{array}$ & AGAATACCAGTCAATCTTTCAC \\
\hline GAPDH & $\begin{array}{l}\text { qPCR analysis of mRNA expression } \\
\text { normalization }\end{array}$ & $\begin{array}{l}\text { F: CCTCAACGACCACTTTGTCAAG } \\
\text { R: TCTTCCTCTTGTGCTCTTGCTG }\end{array}$ \\
\hline $\begin{array}{l}\text { GATA3 5' UTR } \\
\text { (endogenous expression) }\end{array}$ & qPCR analysis of mRNA expression & $\begin{array}{l}\text { F: ACGACCCCTCCAAGATAATTTT } \\
\text { R: GTCGGGGGTCGTTGAATGAT }\end{array}$ \\
\hline $\begin{array}{l}\text { OCT4 3' UTR } \\
\text { (endogenous expression) }\end{array}$ & qPCR analysis of mRNA expression & $\begin{array}{l}\text { F: GGGTTTTTGGGATTAAGTTCTTCA } \\
\text { R: GCCCCCACCCTTTGTGTT }\end{array}$ \\
\hline TFAP2C & qPCR analysis of mRNA expression & F: GGTTGAATCTTCCGGCCG \\
\hline
\end{tabular}




\begin{tabular}{|c|c|c|}
\hline & & R: TCTGCCACTGGTTTACTAGGA \\
\hline TFAP2A & qPCR analysis of mRNA expression & $\begin{array}{l}\text { F: GGACCACCTGGTATTCTGTATTT } \\
\text { R: CTGGGCAACAAAGGACTATGA }\end{array}$ \\
\hline GATA2 & qPCR analysis of mRNA expression & $\begin{array}{l}\text { F: GAACCGACCACTCATCAAGC } \\
\text { R: TTCTTCATGGTCAGTGGCCT }\end{array}$ \\
\hline KRT7 & qPCR analysis of mRNA expression & $\begin{array}{l}\text { F: AAGAACCAGCGTGCCAAGT } \\
\text { R: TCCAGCTCCTCCTGCTTG }\end{array}$ \\
\hline TP63 & qPCR analysis of mRNA expression & $\begin{array}{l}\text { F: AGAAACGAAGATCCCCAGATGA } \\
\text { R: CTGTTGCTGTTGCCTGTACGTT }\end{array}$ \\
\hline HLA-A & qPCR analysis of mRNA expression & $\begin{array}{l}\text { F: GCTCCCACTCCATGAGGTAT } \\
\text { R: AGTCTGTGACTGGGCCTTCA }\end{array}$ \\
\hline ERVFRD-1 & qPCR analysis of mRNA expression & $\begin{array}{l}\text { F: AGCCAACAACATTGACACCA } \\
\text { R: TTTGAAGGACTACGGCTGCT }\end{array}$ \\
\hline $\mathrm{CSH} 1$ & qPCR analysis of mRNA expression & $\begin{array}{l}\text { F: ACTGGGCAGATCCTCAAGC } \\
\text { R: GTCATGGTTGTGCGAGTTTG }\end{array}$ \\
\hline PSG1 & qPCR analysis of mRNA expression & $\begin{array}{l}\text { F: CTAACCCACCGGCACAGTAT } \\
\text { R: TCGACTGTCATGGATTTGGA }\end{array}$ \\
\hline CGB & qPCR analysis of mRNA expression & $\begin{array}{l}\text { F: CAGCATCCTATCACCTCCTGGT } \\
\text { R: CTGGAACATCTCCATCCTTGGT }\end{array}$ \\
\hline SDC1 & qPCR analysis of mRNA expression & $\begin{array}{l}\text { F: CTATTCCCACGTCTCCAGAACC } \\
\text { R: GGACTACAGCCTCTCCCTCCTT }\end{array}$ \\
\hline GCM1 & qPCR analysis of mRNA expression & $\begin{array}{l}\text { F: TGTGAAACTGCCACAGAACG } \\
\text { R: GTGTTTGGCATAGGAATCTGG }\end{array}$ \\
\hline CHSY1 & qPCR analysis of mRNA expression & $\begin{array}{l}\text { F: GTCATGACCGCCCAGAAATA } \\
\text { R: TCCCAGGAATTGTCTTGGAC }\end{array}$ \\
\hline
\end{tabular}




\begin{tabular}{|c|c|c|}
\hline HLA-G & qPCR analysis of mRNA expression & $\begin{array}{l}\text { F: TTGGGAAGAGGAGACACGGAACAC } \\
\text { R: CTCCTTTGTTCAGCCACATTGGCC }\end{array}$ \\
\hline MMP2 & qPCR analysis of mRNA expression & $\begin{array}{l}\text { F: TGGCACCCATTTACACCTACAC } \\
\text { R: ATGTCAGGAGAGGCCCCATAGA }\end{array}$ \\
\hline ITGA1 & qPCR analysis of mRNA expression & $\begin{array}{l}\text { F: GAGCCTATGATTGGAATGGA } \\
\text { R: GGTTGTGTTTCGAGGGATTA }\end{array}$ \\
\hline ITGA5 & qPCR analysis of mRNA expression & $\begin{array}{l}\text { F: CAACATCTGTGTGCCTGACC } \\
\text { R: CCAGGTACACATGGTTCTGC }\end{array}$ \\
\hline KRT18 & qPCR analysis of mRNA expression & $\begin{array}{l}\text { F: CTGCTGCACCTTGAGTCAGA } \\
\text { R: ATGTTCAGCAGGGCCTCATA }\end{array}$ \\
\hline $\mathrm{CDH} 1$ & qPCR analysis of mRNA expression & $\begin{array}{l}\text { F: CTCGACACCCGATTCAAAGT } \\
\text { R: GGCGTAGACCAAGAAATGGA }\end{array}$ \\
\hline OCLN & qPCR analysis of mRNA expression & $\begin{array}{l}\text { F: ACAAATGGACCTCTCCTCCA } \\
\text { R: ATGGCAATGCACATCACAATA }\end{array}$ \\
\hline EPCAM & qPCR analysis of mRNA expression & $\begin{array}{l}\text { F: GCAGCTCAGGAAGAATGTGTC } \\
\text { R: TGAAGTACACTGGCATTGACG }\end{array}$ \\
\hline THY1 & qPCR analysis of mRNA expression & $\begin{array}{l}\text { F: CCAGAACGTCACAGTGCTCA } \\
\text { R: AGGTGTTCTGAGCCAGCAG }\end{array}$ \\
\hline ZEB1 & qPCR analysis of mRNA expression & $\begin{array}{l}\text { F: TTTTCCCATTCTGGCTCCTA } \\
\text { R: TGGTGATGCTGAAAGAGACG }\end{array}$ \\
\hline VIM & qPCR analysis of mRNA expression & $\begin{array}{l}\text { F: CCGACACTCCTACAAGATTTAGA } \\
\text { R: CAAAGATTTATTGAAGCAGAACC }\end{array}$ \\
\hline ACTA2 & qPCR analysis of mRNA expression & $\begin{array}{l}\text { F: GTGACGAAGCACAGAGCAAA } \\
\text { R: TGGTGATGATGCCATGTTCT }\end{array}$ \\
\hline
\end{tabular}




\begin{tabular}{|c|c|c|}
\hline hSOX2 & $\begin{array}{l}\text { qPCR analysis of human-specific } \\
\text { mRNA expression }\end{array}$ & $\begin{array}{l}\text { F: TCTTGGCTCCATGGGTTCG } \\
\text { R: GGGAGGAAGAGGTAACCACA }\end{array}$ \\
\hline mSox2 & $\begin{array}{l}\text { qPCR analysis of mouse-specific } \\
\text { mRNA expression }\end{array}$ & $\begin{array}{l}\text { F: GCTGGGCTCCATGGGCTCT } \\
\text { R: GGGAGGAAGAGGTAACCACG }\end{array}$ \\
\hline Primer pair $A$ & $\begin{array}{l}\text { qPCR analysis of CRISPR/Cas9 } \\
\text { indels }\end{array}$ & $\begin{array}{l}\text { F: TGTACAACATGATGGAGACGGA } \\
\text { R: GCTTGCTGATCTCCGAGTTG }\end{array}$ \\
\hline Primer pair $B$ & $\begin{array}{l}\text { qPCR analysis of CRISPR/Cas9 } \\
\text { indels }\end{array}$ & $\begin{array}{l}\text { F: GGGCGGCGGCGGCAACTCCACC } \\
\text { R: GGGACCACACCATGAAGG }\end{array}$ \\
\hline SOX2-gRNA & $\begin{array}{l}\text { gRNA designed for generation of } \\
\text { indels with pLentiCRISPR system }\end{array}$ & $\begin{array}{l}\text { F: CACCGTGGGCCGCTTGACGCGGTC } \\
\text { R: AAACGACCGCGTCAAGCGGCCCAC }\end{array}$ \\
\hline NANOG-gRNA & $\begin{array}{l}\text { gRNA designed for generation of } \\
\text { indels with pLentiCRISPR system }\end{array}$ & $\begin{array}{l}\text { F: CACCGAGTCGGATGCTTCAAAGCA } \\
\text { R: AAACTGCTTTGAAGCATCCGACTC }\end{array}$ \\
\hline PRDM14-gRNA & $\begin{array}{l}\text { gRNA designed for generation of } \\
\text { indels with pLentiCRISPR system }\end{array}$ & $\begin{array}{l}\text { F: CACCGACCAGGGCAGATCGTAGAG } \\
\text { R: AAACCTCTACGATCTGCCCTGGTC }\end{array}$ \\
\hline
\end{tabular}

Table 1. primer list 
1 Okae, H. et al. Derivation of Human Trophoblast Stem Cells. Cell stem cell 22, 50-63 e56,

$2 \mathrm{Xu}$, J., Du, Y. \& Deng, H. Direct lineage reprogramming: strategies, mechanisms, and applications. Cell stem cell 16, 119-134, doi:10.1016/j.stem.2015.01.013 (2015).

1312

3 Castel, G. et al. Induction of Human Trophoblast Stem Cells from Somatic Cells and Pluripotent

1313 Stem Cells. Cell Rep 33, 108419, doi:10.1016/j.celrep.2020.108419 (2020). Trophoblast-like Transcriptome and Methylome. Stem Cell Reports 15, 198-213, doi:10.1016/j.stemcr.2020.06.003 (2020). induced pluripotent stem cell-derived cystic cells under micromesh culture. Stem Cell Res Ther 10, 245, doi:10.1186/s13287-019-1339-1 (2019).

7 Guo, G. et al. Human naive epiblast cells possess unrestricted lineage potential. Cell stem cell, doi:10.1016/j.stem.2021.02.025 (2021).

8 lo, S. et al. Capturing human trophoblast development with naive pluripotent stem cells in vitro. Cell stem cell, doi:10.1016/j.stem.2021.03.013 (2021).

1326

9 Liu, X. et al. Reprogramming roadmap reveals route to human induced trophoblast stem cells. Nature 586, 101-107, doi:10.1038/s41586-020-2734-6 (2020).

1327

1328

10 Benchetrit, H. et al. Extensive Nuclear Reprogramming Underlies Lineage Conversion into

1329

Functional Trophoblast Stem-like Cells. Cell stem cell 17, 543-556, doi:10.1016/j.stem.2015.08.006 (2015).

1330

1331

1332

Benchetrit, H. et al. Direct Induction of the Three Pre-implantation Blastocyst Cell Types from Fibroblasts. Cell stem cell 24, 983-994 e987, doi:10.1016/j.stem.2019.03.018 (2019).

1333

1334 Cambuli, F. et al. Epigenetic memory of the first cell fate decision prevents complete ES cell

1335 (2014).

13 Kubaczka, C. et al. Direct Induction of Trophoblast Stem Cells from Murine Fibroblasts. Cell

1336 stem cell 17, 557-568, doi:10.1016/j.stem.2015.08.005 (2015).

14 Blakeley, P. et al. Defining the three cell lineages of the human blastocyst by single-cell RNAseq. Development 142, 3613, doi:10.1242/dev.131235 (2015).

15 Petropoulos, S. et al. Single-Cell RNA-Seq Reveals Lineage and X Chromosome Dynamics in Human Preimplantation Embryos. Cell 167, 285, doi:10.1016/j.cell.2016.08.009 (2016).

1337

1338

1339

1340

1341

1342

Deng, Q., Ramskold, D., Reinius, B. \& Sandberg, R. Single-cell RNA-seq reveals dynamic, random monoallelic gene expression in mammalian cells. Science 343, 193-196, doi:10.1126/science.1245316 (2014).

1344

1345

van den Berg, D. L. et al. Estrogen-related receptor beta interacts with Oct4 to positively regulate Nanog gene expression. Molecular and cellular biology 28, 5986-5995, doi:10.1128/MCB.00301-08 (2008).

18 Zhang, X., Zhang, J., Wang, T., Esteban, M. A. \& Pei, D. Esrrb activates Oct4 transcription and sustains self-renewal and pluripotency in embryonic stem cells. The Journal of biological chemistry 283, 35825-35833, doi:10.1074/jbc.M803481200 (2008).

19 Latos, P. A. et al. Fgf and Esrrb integrate epigenetic and transcriptional networks that regulate self-renewal of trophoblast stem cells. Nature communications 6, 7776, doi:10.1038/ncomms8776 (2015). 
$21 \mathrm{Li}, \mathrm{Y}$. et al. BMP4-directed trophoblast differentiation of human embryonic stem cells is mediated through a DeltaNp63+ cytotrophoblast stem cell state. Development 140, 39653976, doi:10.1242/dev.092155 (2013).

1359

22 Krendl, C. et al. GATA2/3-TFAP2A/C transcription factor network couples human pluripotent

1360 stem cell differentiation to trophectoderm with repression of pluripotency. Proceedings of the National Academy of Sciences of the United States of America 114, E9579-E9588, doi:10.1073/pnas.1708341114 (2017).

1363

23 Lee, C. Q. et al. What Is Trophoblast? A Combination of Criteria Define Human First-Trimester

1364 Trophoblast. Stem Cell Reports 6, 257-272, doi:10.1016/j.stemcr.2016.01.006 (2016).

1365

24 Ramsuran, V. et al. Epigenetic regulation of differential HLA-A allelic expression levels. Hum

1366 Mol Genet 24, 4268-4275, doi:10.1093/hmg/ddv158 (2015).

Sebban, S. \& Buganim, Y. Nuclear Reprogramming by Defined Factors: Quantity Versus

1367 Quality. Trends Cell Biol 26, 65-75, doi:10.1016/j.tcb.2015.08.006 (2016).

1368

1369

26 Buganim, Y., Faddah, D. A. \& Jaenisch, R. Mechanisms and models of somatic cell

1370 reprogramming. Nat Rev Genet 14, 427-439, doi:10.1038/nrg3473 (2013).

1371

27 Knofler, M. et al. Human placenta and trophoblast development: key molecular mechanisms

1372 and model systems. Cell Mol Life Sci 76, 3479-3496, doi:10.1007/s00018-019-03104-6 (2019). Prutsch, N. et al. The role of interleukin-1beta in human trophoblast motility. Placenta 33,

1373 696-703, doi:10.1016/j.placenta.2012.05.008 (2012).

29 Kauma, S. W. Cytokines in implantation. J Reprod Fertil Supp/ 55, 31-42 (2000).

30 Soufi, A., Donahue, G. \& Zaret, K. S. Facilitators and impediments of the pluripotency

1374

1375

1376 reprogramming factors' initial engagement with the genome. Cell 151, 994-1004, doi:10.1016/j.cell.2012.09.045 (2012).

31 Gamage, T. K., Chamley, L. W. \& James, J. L. Stem cell insights into human trophoblast lineage differentiation. Hum Reprod Update 23, 77-103, doi:10.1093/humupd/dmw026 (2016). human placenta. Proceedings of the National Academy of Sciences of the United States of America 113, E7710-E7719, doi:10.1073/pnas.1612335113 (2016).

33 Nicola, C., Lala, P. K. \& Chakraborty, C. Prostaglandin E2-mediated migration of human

1385 trophoblast requires RAC1 and CDC42. Biol Reprod 78, 976-982, doi:10.1095/biolreprod.107.065433 (2008).

1386

1387

34 Wang, L. et al. Reduced ELABELA expression attenuates trophoblast invasion through the 1388 $\mathrm{PI3K/AKT/mTOR} \mathrm{pathway} \mathrm{in} \mathrm{early} \mathrm{onset} \mathrm{preeclampsia.} \mathrm{Placenta} \mathrm{87,} \mathrm{38-45,}$ doi:10.1016/j.placenta.2019.08.077 (2019).

1389

1390

35 Weissbein, U., Plotnik, O., Vershkov, D. \& Benvenisty, N. Culture-induced recurrent epigenetic

1391 aberrations in human pluripotent stem cells. PLoS Genet 13, e1006979, doi:10.1371/journal.pgen.1006979 (2017).

1392

1393

Coorens, T. H. H. et al. Inherent mosaicism and extensive mutation of human placentas.

1394 Nature 592, 80-85, doi:10.1038/s41586-021-03345-1 (2021).

37 Apostolou, E. \& Hochedlinger, K. Chromatin dynamics during cellular reprogramming. Nature 502, 462-471, doi:10.1038/nature12749 (2013).

1396

1397

38 Vargas, A. et al. Syncytin-2 plays an important role in the fusion of human trophoblast cells. $J$

1398 Mol Biol 392, 301-318, doi:10.1016/j.jmb.2009.07.025 (2009).

1399

1400

Liu, Y. et al. Single-cell RNA-seq reveals the diversity of trophoblast subtypes and patterns of

1401 differentiation in the human placenta. Cell Res 28, 819-832, doi:10.1038/s41422-018-0066-y

40 Okita, K. et al. A more efficient method to generate integration-free human iPS cells. Nat 1403 Methods 8, 409-412, doi:10.1038/nmeth.1591 (2011).

1404

41 Osafune, K. et al. Marked differences in differentiation propensity among human embryonic 1405 stem cell lines. Nat Biotechnol 26, 313-315, doi:10.1038/nbt1383 (2008). 
42 Haider, S. et al. Self-Renewing Trophoblast Organoids Recapitulate the Developmental Program of the Early Human Placenta. Stem Cell Reports 11, 537-551, doi:10.1016/j.stemcr.2018.07.004 (2018).

1408

1409

43 Turco, M. Y. et al. Trophoblast organoids as a model for maternal-fetal interactions during

1410 human placentation. Nature 564, 263-267, doi:10.1038/s41586-018-0753-3 (2018).

1411

44 Takahashi, K. et al. Induction of pluripotent stem cells from adult human fibroblasts by defined

1412 factors. Cell 131, 861-872, doi:10.1016/j.cell.2007.11.019 (2007). Through the Suppression of Reprogramming-Induced Senescence. J Cell Physiol 231, 17191727, doi:10.1002/jcp.25270 (2016).

46 Esteban, M. A. et al. Vitamin C enhances the generation of mouse and human induced pluripotent stem cells. Cell stem cell 6, 71-79, doi:10.1016/j.stem.2009.12.001 (2010). Shalem, O. et al. Genome-scale CRISPR-Cas9 knockout screening in human cells. Science 343, 84-87, doi:10.1126/science.1247005 (2014).

48 Fong, H., Hohenstein, K. A. \& Donovan, P. J. Regulation of self-renewal and pluripotency by Sox2 in human embryonic stem cells. Stem Cells 26, 1931-1938, doi:10.1634/stemcells.20071002 (2008).

49 Pastor, W. A. et al. Naive Human Pluripotent Cells Feature a Methylation Landscape Devoid of Blastocyst or Germline Memory. Cell stem cell 18, 323-329, doi:10.1016/j.stem.2016.01.019 (2016).

1424

1425

1426

50 Adachi, K. et al. Context-dependent wiring of Sox2 regulatory networks for self-renewal of embryonic and trophoblast stem cells. Mol Cell 52, 380-392, doi:10.1016/j.molcel.2013.09.002 (2013). 33, e179, doi:10.1093/nar/gni178 (2005).

52 Boyle, P. et al. Gel-free multiplexed reduced representation bisulfite sequencing for largescale DNA methylation profiling. Genome Biol 13, R92, doi:10.1186/gb-2012-13-10-r92 (2012). Mendenhall, E. M. et al. Locus-specific editing of histone modifications at endogenous enhancers. Nat Biotechnol 31, 1133-1136, doi:10.1038/nbt.2701 (2013).

1435

54 Buenrostro, J. D., Giresi, P. G., Zaba, L. C., Chang, H. Y. \& Greenleaf, W. J. Transposition of 1436 native chromatin for fast and sensitive epigenomic profiling of open chromatin, DNA-binding 1437 proteins and nucleosome position. Nat Methods 10, 1213-1218, doi:10.1038/nmeth.2688 1438 (2013).

55 Love, M. I., Huber, W. \& Anders, S. Moderated estimation of fold change and dispersion for 1439 RNA-seq data with DESeq2. Genome Biol 15, 550, doi:10.1186/s13059-014-0550-8 (2014).

1441

1442

1443 Bioinformatics 10, 232, doi:10.1186/1471-2105-10-232 (2009).

57 Krueger, F. \& Andrews, S. R. Bismark: a flexible aligner and methylation caller for Bisulfite-Seq applications. Bioinformatics 27, 1571-1572, doi:10.1093/bioinformatics/btr167 (2011).

58 Langmead, B. \& Salzberg, S. L. Fast gapped-read alignment with Bowtie 2. Nat Methods 9, 357359, doi:10.1038/nmeth.1923 (2012).

1444

1445

1446

1447

$59 \mathrm{Li}, \mathrm{H}$. \& Durbin, R. Fast and accurate short read alignment with Burrows-Wheeler transform.

1448

Bioinformatics 25, 1754-1760, doi:10.1093/bioinformatics/btp324 (2009).

1449

60 Zhang, Y. et al. Model-based analysis of ChIP-Seq (MACS). Genome Biol 9, R137, doi:10.1186/gb-2008-9-9-r137 (2008).

61 McLean, C. Y. et al. GREAT improves functional interpretation of cis-regulatory regions. Nat Biotechnol 28, 495-501, doi:10.1038/nbt.1630 (2010). 